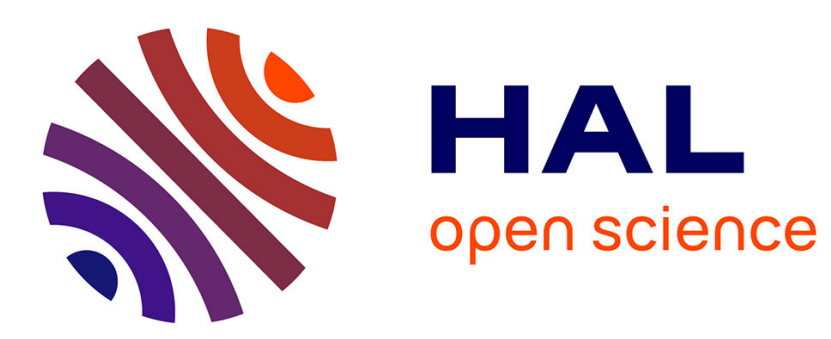

\title{
New lineages of Lebinthini from Australia (Orthoptera: Gryllidae: Eneopterinae)
}

\author{
Tony Robillard, You Ning Su
}

\section{To cite this version:}

Tony Robillard, You Ning Su. New lineages of Lebinthini from Australia (Orthoptera: Gryllidae: Eneopterinae). Zootaxa, 2018, 4392 (2), pp.241-266. 10.11646/zootaxa.4392.2.2 . hal-01787494

\section{HAL Id: hal-01787494 https://hal.sorbonne-universite.fr/hal-01787494}

Submitted on 7 May 2018

HAL is a multi-disciplinary open access archive for the deposit and dissemination of scientific research documents, whether they are published or not. The documents may come from teaching and research institutions in France or abroad, or from public or private research centers.
L'archive ouverte pluridisciplinaire HAL, est destinée au dépôt et à la diffusion de documents scientifiques de niveau recherche, publiés ou non, émanant des établissements d'enseignement et de recherche français ou étrangers, des laboratoires publics ou privés. 
New lineages of Lebinthini from Australia (Orthoptera: Gryllidae: Eneopterinae)

TONY ROBILLARD ${ }^{1} \&$ YOU NING SU ${ }^{2}$

${ }^{1}$ Muséum national d'Histoire naturelle, Institut de Systématique, Évolution, Biodiversité, ISYEB - UMR 7205 - CNRS, MNHN, UPMC, EPHE, Sorbonne Université, 57 rue Cuvier, CP50, F-75005, Paris, France

${ }^{2}$ Australian National Insect Collection, CSIRO National Research Collections Australia, PO Box 1700, Canberra, ACT 2601

\begin{abstract}
A monograph concerning the Australian crickets was published in 1983 by Otte \& Alexander, but this territory still harbors many undiscovered, undescribed treasures. Both existing species of Australian Lebinthus prove to belong to the tribe Eurepini. Our study results in the following new combinations: Salmanites miripara (Otte \& Alexander, 1983) n. comb. and Eurepa bifasciata (Chopard, 1951) n. comb. In the meantime, newly collected material from northern Queensland allow us to describe two new lineages of brachypterous Lebinthini from northern Australia, the species Macrobinthus kutini n. sp., and the new genus Julverninthus and the species Julverninthus rentzi $\mathrm{n}$. $\mathrm{sp}$. and Julverninthus minoris $\mathrm{n}$. $\mathrm{sp}$.
\end{abstract}

Keywords: Lebinthini, Eurepini, taxonomy, Australia, new genus, new species 


\section{INTRODUCTION}

The crickets of the tribe Lebinthini (subfamily Eneopterinae) are mainly distributed in Southeast Asia and in the archipelagos of the Western Pacific. Most of the brachypterous Lebinthini form a monophyletic group corresponding to genera diversified both morphologically and acoustically (Robillard et al. 2016), and being more or less related to the genus Lebinthus Stål, 1877, as suggested by recent phylogenetic studies (Nattier et al. 2011; Anso et al. 2016; Vicente et al. 2017). Most of these genera have been recently described from New Guinea (Robillard 2011; Vicente et al. 2015; Robillard et al. 2016) and New Caledonia (Anso et al. 2016). Until now, the brachypterous Lebinthini were only represented in Australia by two species of the genus Lebinthus, which status has not been questioned, Lebinthus miripara Otte \& Alexander, 1983, and Lebinthus bifasciatus Chopard, 1951 (Otte \& Alexander, 1983). This lack of diversity could indicate either that this clade did not diversify in Australia, despite favourable climatic conditions, especially in the north of the continent, or that this diversity has not been discovered yet.

In this study, we revise the Australian Lebinthus which consists of two species both of which prove to belong to the tribe Eurepini. We assess material from recent field collections and describe two new lineages of brachypterous Lebinthini from northern Australia: Macrobinthus kutini n. sp., and the new genus Julverninthus with the species Julverninthus rentzi n. sp. and Julverninthus minoris $\mathrm{n}$. sp. We provide information about species distribution, illustrate male and female genitalia, forewing venation and habitats. 


\section{MATERIAL AND METHODS}

\section{Material examined}

Specimens studied herein were deposited in Australian National Insect Collection, CSIRO, Canberra, Australia (ANIC), with paratypes deposited in the Muséum national d'Histoire naturelle, Paris, France (MNHN). Square brackets in lists of materials are used for additional information not mentioned on specimen labels.

\section{Observations and morphological analysis}

Descriptions were made according to the standards of recent publications concerning new species of Lebinthini genera (e.g., Vicente et al. 2015; Robillard et al. 2016). Direct observations and dissections were made using a binocular microscope Leica MZ16 at magnifications up to 115. Male tegminal veins and cells are named after Vicente et al. (2015) and Robillard \& Desutter-Grandcolas (2004). Male and female genitalia have been dissected in softened specimens by cutting the membranes between the paraprocts and the subgenital plate, or between the ovipositor and the subgenital plate, respectively; they have been cleaned with cold $\mathrm{KOH}$ and then kept in glycerine in vials pinned under each specimen. Male genitalia are named according to Desutter (1987), modified in Desutter-Grandcolas (2003) and Robillard \& Desutter-Grandcolas (2004). Photographs of male and female genitalia were obtained using an AmScope MU1000 digital camera (www.Amscope.com). Genitalia were stained with a drop of Punktol (JLB, Germany) and photographed in Hand sanitizer (Su 2016). Abbreviations: see below.

\section{DNA sequencing}

Several specimens of a given morphology were analyzed using DNA barcoding to confirm that they belong to the same species. We used a tree-based approach with a maximum likelihood tree reconstructed with the IQ-TREE web service (Nguyen et al. 2015). We used a fragment of the small mitochondrial ribosomal subunit (12S rRNA, $\sim 400 \mathrm{bp}$ ), easy to amplify and which proved to be variable between closely related species in crickets (e.g., Robillard \& Desutter-Grandcolas 2006; Nattier et al. 2012). Molecular works were performed at the "Service de Systématique Moléculaire" of the MNHN. DNA extractions were made from median legs of crickets using the Epmotion 5075 robot (Eppendorf). All sequences were 
generated using the amplification and sequencing protocols described in Nattier et al. (2012), with similar primers and annealing temperatures. Newly generated sequences were edited in Sequencher v.4.9 (Gene Codes Co.) and BioEdit v.7.0.5.3 (Hall 1999), blasted with NCBI blast tools and compared; the data will be published as part of a phylogenetic study of the Lebinthini in preparation.

\section{Abbreviations}

\section{Descriptions.}

General morphology: FI-II-III, femur of fore, median and hind leg; FW, forewing; HW, hind wing; TI-II-III, tibia of fore, median and hind leg; Tarsomere III-1, III-3: first and third segments of hind leg tarsomere.

Tegminal venation: $1 \mathrm{~A}-4 \mathrm{~A}$, first to fourth anal veins; CuA, anterior cubitus; CuA1, CuA2, ... first, second, ... bifurcations of CuA; CuP, posterior cubitus; M, median vein; R, radial vein; Sc, subcostal vein, c1-3, first to third cells of $C$ alignment; d1 cell (mirror), first cell(s) of D alignment.

Male genitalia: ect ap: ectophallic apodeme; ect arc: ectophallic arc; ect fo: ectophallic fold; end sc: endophallic sclerite; pse pa: pseudepiphallic paramere.

\section{Institutions}

ANIC Australian Natural Insect Collection, Canberra, Australia.

MNHN Muséum national d'Histoire naturelle, Paris, France.

QM Queensland Museum, Brisbane, Australia.

SAM South Australia Museum, Adelaide, Australia.

\section{Measurements}

FIIIL, length of hind femora; FIIIW, width of hind femora; FWL, forewing length; FWW, forewing width (at the level of maximal width); OL, ovipositor length; PronL, pronotum length; PronW, pronotum width; TIIIL, length of hind tibiae. 


\section{SYSTEMATIC PART}

Family GRYLLIDAE

Subfamily Eneopterinae Saussure, 1874

Tribe Eurepini Robillard, 2004

Salmanites Chopard, 1951

Salmanites Chopard, 1951: 483

Type species. Salmanites obscurifrons Chopard, 1951, by original monotypy.

Salmanites miripara (Otte \& Alexander, 1983) n. comb.

(Figs 1, 2)

http://lsid.speciesfile.org/urn:Isid:Orthoptera.speciesfile.org:TaxonName:500992

Lebinthus miripara Otte \& Alexander, 1983: 308. Robillard \& Desutter-Grandcolas 2004: 291. Cigliano et al. 2017 (Orthoptera Species File Online)

Type material. Male holotype, Australia. Holotype male, A-694, 85 miles N of Geraldton, WA, 10.v.1969, Alexander \& Otte (ANIC) [examined]. Paratypes (1+): Australia. Same information as HT (ANIC) [examined].

Additional material examined. Australia, 50 mi ENE of Meekatharra, WA, 29.iv.1963, 1을 L.J. Chinnick (ANIC).

Discussion. Close examination of the type series revealed that the species belongs to the tribe Eurepini, based on the definition of the eneopterine tribes and the key of Robillard (2006). The following characters were examined to support this transfer: inner tympanum absent, membrane of outer tympanum smooth, male FW venation with CuP extending posteriorly beyond file level, male subgenital plate without swellings on dorsal margin, male genitalia with ramal plates, lateral arms of endophallic sclerite directly prolonged by sclerotization of ectophallic fold. 
The attribution of the species to one of the five genera currently included in the tribe Eurepini is more speculative. Based on head morphology with fastigium three times as wide as scape, it could belong to either Salmanites or Eurepella and differs from Eurepa and Myara. The general shape of male genitalia excludes Myara and Eurepa, but could correspond to Salmanites, Arilpa and Eurepella. Finally, there are strong setae oriented anteriorly on dorsolateral margins of pseudepiphallus, which is a characteristic of Salmanites and Arilpa (Robillard \& Desutter-Grandcolas 2004). Male FW venation reveals that mirror is entirely absent, which is the only recorded case in Eurepini (even the short winged species in Arilpa and Salmanites possess a mirror cell) (Otte \& Alexander 1983). Female ovipositor as long as FIII, points toward Eurepa, Myara or Salmanites. In conclusion, the species could either correspond to a new genus, given the original combination of characters, or to a very diverging species of Salmanites. In a conservative way, we considered it as Salmanites miripara n. comb., but this hypothesis will have to be tested in forthcoming revisions of the Eurepini genera and with molecular evidence.

Eurepa Walker, 1869

Eurepa Walker, 1869: 71

Type species. Acheta marginipennis White, 1841, by original monotypy

Eurepa bifasciata (Chopard, 1951) n. comb.

(Figs 3, 4)

http://lsid.speciesfile.org/urn:Isid:Orthoptera.speciesfile.org:TaxonName:500993

Lebinthus bifasciatus Chopard, 1951: 482. Chopard 1968: 354. Otte \& Alexander 1983: 308. Robillard \& Desutter-Grandcolas 2004: 291. Cigliano et al. 2017 (Orthoptera Species File Online).

Type material. Male holotype, Australia. Northern Territory, Daly River, H. Wesselman (SAM) [not examined]. Female allotype, Australia. N.T. [Northern Territory], G.H. Hill, Mary Riv[er], syntype + T10780, photographed specimen (QM) [examined]. Northern Territory, Port Darwin, $1 \delta^{\Uparrow}$ (SAM) [not examined]. 
Additional materials examined. Australia. Tindal, 8 mi ESE of Katherine, NT [Northern Territory], 14.31S 132.22E, 6.xii.1967, 10; 5.xii.1967, 1, W.J.M. Vestjens (ANIC). 5 mi. NW of Adelaide River (town) NT, 31.x.1965, 1今, A. Mesa \& R. Sandulski (ANIC). Kapalga (CSIRO Research Site), NT, 12.40S 132.24E, 1.xi.1991, 5ð, 2 \%, D.C.F. Rentz stop 61 (ANIC Database NO.14-008552 - 14-008556) (ANIC, MNHN). Pethericks Rainforest Reserve, Litchfield Park NT, 13.07S 130.40E, 29.x.1991, 39, D.C.F. Rentz stop 56 (ANIC Database NO.14-008558, 14-008661, 14-008662) (ANIC)

Discussion. Close examination of the type series revealed that this species also belongs to the tribe Eurepini, based on the definition of the eneopterine tribes and the key of Robillard (2006). The following characters were examined to support this transfer as for L. miripara: inner tympanum absent, membrane of outer tympanum smooth, male FW venation with CuP extending posteriorly beyond file level, male subgenital plate without swellings on dorsal margin; male genitalia with ramal plates, lateral arms of endophallic sclerite directly prolonged by sclerotization of ectophallic fold, female apex of ventral valve of ovipositor entirely covered by dorsal valves; female apex of ventral valve of ovipositor entirely covered by dorsal valves. In addition, the epistomal suture on face is interrupted between the tentorial insertions, with a transversal furrow underlying the median ocellus, which is only found in Eurepini genera.

As for the previous species, the attribution of the species to one of the five Eurepini genera is very speculative. Male FW venation with a small mirror, not rounded, points toward Salmanites and Arilpa. The female type has no wings (Chopard 1951; Figs. 3A,B,E). However female non-type specimens all show wings reaching abdomen mid-length (Fig. 3F), which may indicate that the species is winged but that Chopard's allotype lost its wings; it remains compatible with Salmanites and some Eurepa species, which include winged and almost apterous species (Otte \& Alexander 1983). The large size of the ovipositor (2.5 longer than FIII) would exclude Eurepella and Arilpa, and is compatible with Eurepa and Myara. The general shape of the male genitalia and in particular the shape of the pseudepiphallic parameres with anterior projections is, however, clearly a characteristic of Eurepa. In conclusion, the species could either correspond to a new genus, given the original combination of characters, or to a very diverging species of Eurepa or Salmanites. In a conservative way, we consider the species as Eurepa bifasciata n. comb., but this hypothesis will have to be tested in a forthcoming revision of the Eurepini genera and with molecular evidence. 


\section{Tribe Lebinthini Robillard, 2004}

\section{Julverninthus $\mathbf{n}$. gen.}

(Figures 5-8, 9A, 10A-F, 11-13, 18)

Type species. Julverninthus rentzi, here designated.

Etymology. Genus named after Lebinthus and the prefix "Julvern" corresponding to the contraction of Jules Vernes (1828-1905). This famous French author wrote many adventure novels, among which "Around the world in eighty days". Given that Eneopterinae have travelled around the world after originating from Australia-Antarctica ca. $80 \mathrm{Ma}$ (Vicente et al. 2017), it is an appropriate name for the first endemic genus "coming back" to Australia. Masculine gender.

Distribution. Australia, Northern Queensland.

Diagnosis. Among the brachypterous Lebinthini genera, Julverninthus is characterized by its setose, trapezoidal fastigium, almost as long as wide, forming a wide rostrum. Eyes smaller and less prominent than in Lebinthus and Macrobinthus, but larger than in Centuriarus and Agnotecous. The genus mostly resembles Macrobinthus in size and general shape, but differs by its very short wings resembling that of Microbinthus in both sexes. Male. FWs very short, dorsal field longer than lateral field (almost of similar size in Lebinthus and Macrobinthus). Harp forming an equilateral triangle, with one main bisinuated oblique vein; posterior edge of harp almost flat along diagonal vein. $1 \mathrm{~A}$ vein slightly bisinuate anterior to angle, as in Ligypterus, Gnominthus and Cardiodactylus, differing from most brachypterous genera. Mirror little differentiated, cell d1 rectangular. Cell c1 large, trapezoidal, with variable accessory veins. Chord veins delimiting a narrow, semi-circular cell. Apical field very short, including only a small area posterior to mirror with reticulated veins and no cell alignment. Median fold well developed, located on dorsum. Sc vein with 1-2 projections. Male genitalia elongate, characterized by absence of individualized apical lophi, with a long median process, as in Pixibinthus and Macrobinthus wilhelmsis and some species of Agnotecous. Female. FWs very short, barely reaching posterior margin of first sternite, well separated, rounded posteriorly. Ovipositor shorter than FIII, its apex acute, slightly denticulate on dorsal edge. Female copulatory papilla rounded, almost entirely membranous; apex rounded, generally folded ventrally. 
Description. Size average for the tribe. Vertex prolonged discontinuously by trapezoidal fastigium almost as long as wide. Eyes of average size, in dorsal view, eyes combined width represents ca. 41\% of head width (37\% in Agnotecous azurensis Desutter-Grandcolas, 2006, 50\% in Microbinthus santoensis (Robillard, 2009), 46\% in Lebinthus bitaeniatus Stål, 1877). Head triangular in facial view, slightly higher than wide; vertex rounded. Ocelli whitish, small and rounded, forming a wide triangle. Scapes small. Pronotum dorsal disk almost square, wider than long, its posterior margin straight; lateral lobe longer than high. $\mathrm{Tl}$ with two tympana; inner tympanum covered by a flat sclerotized expansion, its membrane visible along a small longitudinal slit only; outer tympanum ellipsoidal, its membrane transversally plicate in dorsal half. TI with two inner and one outer apical spurs. TII with two inner and two outer spurs. FIII muscular and long, with a linear region before knee. TIII serrulated on their whole length, slightly furrowed longitudinally and with four pairs of subapical spurs and three pairs of apical spurs; inner spurs long and curved, outer spurs shorter and straight. Talll-1 with two dorso-apical spines and a row of spines on outer dorsal edge; without lateral outer spine. FWs very short, not reaching abdomen mid-length; hind wings absent. Cerci well developed, nearly as long as abdomen.

Male. Metanotal glands absent. Dorsal field of FWs clearly longer than lateral field. FWs very short, nearly the size of pronotum dorsal disk. FW venation: $1 \mathrm{~A}$ vein (file) bisinuate near angle; stridulatory file with teeth both on transverse and on angle parts of $1 \mathrm{~A}$. Harp forming an equilateral triangle, with one main, sharp-angled, bisinuated oblique vein; posterior edge of harp almost flat along diagonal vein. CuP absent. CuA strong, slightly curved inward near apex. Mirror well differentiated but not rounded, forming a wide rectangular area. Cell c1 large, sometimes with a median transverse accessory vein. Chord cells differentiated, the inner one forming a narrow semi-circular ring. Apical field very short, including only a small area posterior to mirror with reticulated veins and no cell alignment. Median fold welldeveloped, triangular, located on dorsum. M strong and convex, fused to R near FW apex; Sc with 1-2 projections. Subgenital plate clog-shaped, slightly indented apically; inner side of subgenital plate with lateral swellings.

Male genitalia: Pseudepiphallus triangular, elongate, basal margin straight, posterior apex elongate, without paired lophi and forming a gutter, setose ventrally (Figs. 8,13). Rami straight, parallel and short. Ventral pseudepiphallic plate wide. Pseudepiphallic parameres sclerotized, convergent, their basis strong, with two posterior lobes, one oriented dorsally and one forming a rounded ventral plate, and a small basal lobe mostly membranous. Ectophallic apodemes parallel and long, their apex lamellate. Ectophallic arc wide, well sclerotized, with a short medioposterior expansion. Ectophallic fold long, with elongate lateral sclerites forming a ")(“" pattern; its apex triangular and membranous. Endophallic sclerite 
large, comprising posteriorly a short median expansion and lateral arms; sclerite very long anteriorly, Y-shaped, exceeding pseudepiphallic sclerite. Endophallic apodeme with welldeveloped lateral lamellas and a narrow dorsal crest.

Female. FWs very short, barely reaching posterior margin of first sternite, well separated from each other, rounded posteriorly; dorsal field with more or less distinct longitudinal veins; lateral field with longitudinal veins curved dorsally. Ovipositor shorter than FIII, its apex acute, slightly denticulate on dorsal edge. Female copulatory papilla rounded, almost entirely membranous, without ventral sclerite nor basal plate; apex rounded, generally folded ventrally.

Habitat and life history traits. Activity nocturnal, the species lives in or near leaf litter, usually on low vegetation, in forested areas.

\section{Included species.}

Julverninthus rentzi n. sp.

Julverninthus minoris n. sp. 


\section{Julverninthus rentzi $\mathrm{n} . \mathrm{sp}$.}

(Figs 5A-D, 6A-C, 7A, B, 8, 9A, 10A-C, 11, 12, 18)

http://lsid.speciesfile.org/urn:Isid:Orthoptera.speciesfile.org:TaxonName:500995

Type material. Male holotype: Australia, Queensland, Daintree rainforest, Observatory, 5.v.2015, $16^{\circ} 06^{\prime}$ S $145^{\circ} 26^{\prime}$ E, 49 m, B. Lessard, Y.N. Su \& K. Meusermann, molecular sample L119 (ANIC database no.14-005045). Female: Australia, Queensland, James Cook University, rainforest site, 1606'11.53"S 145²7'13.08"E, 19 m, 18-19.viii.2014, D.C.F. Rentz, P. Tripotin \& B. Richardson, 19 matured in laboratory (6.xii/2014) (ANIC). Paratypes (2§): Australia, Queensland, Cape Tribulation, 16.05S, 145.27E QLD, CT3, 30 m, 2 km WSW, 4.i.1996, 1ð, molecular sample L123, L. Umback FI trap-JCU (ANIC database no.14005044). James Cook University, rainforest site, 1606'10.00"S 145²6'56.24"E, $46 \mathrm{~m}$, 10.iii.2014, 1 đ̊, D.C.F. Rentz \& B. Richardson (MNHN-EO-ENSIF4386).

Type locality. Australia, Queensland, Daintree rainforest, Observatory, 5.v.2015, $16^{\circ} 06^{\prime} S$ $145^{\circ} 26^{\prime} \mathrm{E}, 49 \mathrm{~m}$.

Distribution. Australia, Queensland.

Etymology. Species dedicated to the great Australian entomologist David Rentz, who collected the type specimens.

Diagnosis. J. rentzi is characterized by its larger size, dark orange brown coloration with darker head and lateral lobes of pronotum, female FW venation with strong longitudinal veins (reticulated in J. minoris), and by male genitalia with pseudepiphallus more elongate and thinner than in J. minoris, not convex dorsally; pseudepiphallic parameres with a rectangular dorsal lobe (rounded in J. minoris), their bases parallel (diverging in J. minoris).

Description. Size average. Coloration mostly orange brown, except head and pronotum darker (Figs. 5A-D). Eyes small, occupying 35\% of head width dorsally. Vertex with five wide longitudinal black bands on yellow background, the median one resulting from the fusion more or less complete of two bands (Fig. 6A). Fastigium dark brown twice as wide as scape, densely setose, with short whitish setae and longer orange ones. Ocelli whitish. Scapes orange brown, with a black pattern on facial side; antennae light brown basally, then darker with yellow brown rings. Front and face black, with a yellow spot bellow eyes. Lateral side of head black, with two faint yellow lines posterior to eyes. Mouthparts dark brown; clypeus with two lateral yellow spots on dorsal margin and a characteristic trident-shaped whitish pattern on ventral part (Fig. 6B); mandibles black basally, yellow ventrally; labrum brown basally, then whitish. Maxillary palpi brown. Pronotum: Dorsal disk brown, mottled with orange, and black; lateral lobes homogeneously black. Wings brachypterous, very short in both sexes. 
Legs almost homogeneously dark orange brown; tarsomeres yellow basally. FIII dark orange brown, including knees, mottled with white spots and with dark striated patterns. Abdomen and cerci orange brown, the latter mottled with dark brown.

Male: FWs dorsal field (Fig. 7A) translucent brown with yellow veins, its antero-lateral corner with a large whitish sclerotization (hidden under pronotum in HT, but see Fig. 11); area of plectrum with a strong orange sclerotization. Vein $1 \mathrm{~A}$ bisinuate anterior to angle. File with 159 stridulatory teeth distributed on transverse part of $1 \mathrm{~A}$ (130) and on angle (29). CuA barely curved inward. CuP absent. Mirror not rounded by well differentiated from other cells of $D$ alignment, forming a wide rectangle without accessory vein. Cell $c 1$ widened posteriorly, with a median transverse vein. Apical field short, including reticulated veins posterior to mirror (cell alignment E). Lateral field mostly dark brown; veins $\mathrm{R}$ and $\mathrm{M}$ strong and orange, delimiting a dark brown area. Sc orange, with two projections. Lateral field with four $(n=3)$ strong parallel longitudinal veins ventral to Sc, with faint dark transverse veins.

Male genitalia (Fig. 8): Pseudepiphallus elongate, forming a narrow triangle; posterior apex forming a gutter longer than wide; pseudepiphallus straight in lateral view. Pseudepiphallic parameres dorsal posterior lobe rectangular with rounded angles; their bases parallel.

Female. FWs very short, separated dorsally by half their length, apex rounded (Fig. 7B). FW dorsal field light brown, not translucent, lateral field dark brown; FW with $10(n=1)$ strong dark brown strong longitudinal veins, 7 on dorsal field, 3 on lateral field. Ovipositor slightly shorter than FIII, apex acute, slightly denticulate dorsally (Fig. 9A). Female copulatory papilla (Figs. $10 A-C)$ : rounded, flat ventrally; apex slightly sclerotized and folded ventrally.

Juvenile: Brown, with similar color pattern as in adults (Fig. 12B).

Measurements - See Table 1.

Habitat and life history traits - J. rentzi was found active at night on low plants in forested areas.

Calling song - Unknown. 


\section{Julverninthus minoris $\mathrm{n}$. sp.}

(Figs 5E-H, 6D-F, 7C, 10D-F, 13, 18)

http://lsid.speciesfile.org/urn:Isid:Orthoptera.speciesfile.org:TaxonName:500997

Type material. Male holotype: Australia, Queensland, Clohesy Riv.[er] Rd.[road] QLD, 16.7 km from Kennedy Hwy [highway], electricity tower, 1658.599'S 145³9.358'E (car), 621 m, 15.ii.2016, D.C.F. Rentz, Stop 10, molecular sample L126 (ANIC Database NO.14009141). Female: Australia, Queensland, Bellenden Ker Range, NO, 1/2 km S. Cable Tower No.7, 500 m, 17-24.x.1981, Earthwatch/Qld Museum (ANIC Database NO.14-009143). Paratypes (2 + ): Australia, Queensland, 1q, same information as AT (ANIC Database NO.14-009142). Mt Lewis Rd via Julatten, 3.8 km from Jct. QLD., 16³4'S 145¹8'E (GPS), 542 m, 11.v.2012, 1으. D.C.F. Rentz \& B. Richardson, Stop 12-20, molecular sample L144 (MNHN-EO-ENSIF4387).

Other material examined. Australia, Queensland, Mt Lewis Rd via Julatten, $5.5 \mathrm{~km}$ from Jct. QLD., 16³'S 145 18'E (GPS), 713 m, 15.IX.2014, 1 juvenile, D.C.F. Rentz \& B. Richardson, Stop 12-24, molecular sample L143 (ANIC Database NO.14-009140)

Type locality. Australia, Queensland, Clohesy River road, 16.7 km from Kennedy highway, electricity tower.

Distribution. Australia, Queensland.

Etymology. Species named after its small size.

Diagnosis. J. minoris is characterized by its smaller size, dark brown coloration more homogeneous than in J. rentzi, short stocky FIII, female FW venation reticulated, and following characters in male genitalia: with pseudepiphallus wider and shorter than in $J$. rentzi, convex dorsally in lateral view; pseudepiphallic parameres with a rounded dorsal lobe (more rectangular in $\mathrm{J}$. rentzi), their bases diverging (parallel in J. rentzi).

Description. Size small. Coloration mostly dark brown (Figs 5E-H). Eyes small, dark brown with a wide pink dorsal band in living specimens (Fig. 5E); eyes occupying ca. 35\% of head width dorsally. Vertex with five wide longitudinal black bands on orange brown background, the median one resulting from the fusion more or less complete of two bands (Fig. 6D). Fastigium orange brown twice as wide as scape, densely setose. Ocelli whitish. Scapes orange brown, with a black pattern on facial side; antennae light brown basally, then darker with yellow brown rings. Frons dark brown, with two black dorsal spots. Face dark brown, 
with a yellow spot bellow eyes. Lateral side of head dark brown, with two faint yellow lines posterior to eyes. Mouthparts homogeneously dark brown in HT, but some specimens with similar pattern of coloration as in J. rentzi: clypeus with two lateral yellow spots on dorsal margin and a faint trident-shaped whitish pattern on ventral part (Fig. 6B); mandibles black basally, yellow ventrally; labrum brown. Maxillary palpi brown. Pronotum: Dorsal disk homogeneously brown; lateral lobes homogeneously black. Wings brachypterous, very short in both sexes. Legs orange brown; FI-II with dark brown spots, TI-II with a faint lighter ring; tarsomeres yellow basally. FIII short and stocky; mostly orange brown, knees dark brown, mottled with white spots and with dark striated patterns. Tall-1 with one lateral spine on lateral external side in HT and 1 PT. Abdomen dark brown; cerci orange brown mottled with dark brown basally, with dark rings apically.

Male: FWs dorsal field (Fig. 7C) translucent brown with yellow veins, its antero-lateral corner with a large whitish sclerotization; area of plectrum with a strong orange sclerotization. Vein $1 \mathrm{~A}$ bisinuate anterior to angle. File with 116 stridulatory teeth distributed on transverse part of $1 \mathrm{~A}$ (107) and on angle (9). CuA barely curved inward. CuP absent. Mirror not rounded but well differentiated from other cells of $D$ alignment, forming a wide rectangle. Cell $c 1$ not widened posteriorly, without transverse vein. Apical field short, with faint reticulated veins posterior to mirror (cell alignment E). Lateral field homogeneously dark brown (veins and cells); veins $\mathrm{R}$ and $\mathrm{M}$ strong, delimiting a darker area; Sc with one preapical projection. Lateral field with five $(n=1)$ strong parallel longitudinal veins ventral to Sc, with faint dark transverse veins.

Male genitalia (Fig. 13): Pseudepiphallus triangular, less elongate than in J. rentzi; convex dorsally in lateral view; posterior apex forming a gutter barely longer than wide (Fig. 13A). Pseudepiphallic parameres dorsal posterior lobe rounded; their bases diverging.

Female. FWs very short, separated dorsally by half their length, apex rounded; its venation mostly reticulated. Ovipositor slightly shorter than FIII, apex acute, slightly denticulate dorsally. Female copulatory papilla (Figs. 10D-F): rounded, flat ventrally; apex slightly sclerotized and folded ventrally.

Juvenile: Brown, with similar color pattern as in adults.

Measurements. See Table 2.

Habitat and life history traits. J. minoris was found active at night on low plants in forested areas.

Calling song. Unknown. 
Macrobinthus Robillard \& Dong, 2016

Macrobinthus Robillard \& Dong, 2016: 168.

Type species: Larandopsis jharnae Bhowmik, 1981, by original designation.

Distribution. North-east New Guinea Island (Papua New Guinea and Papua province of Indonesia), New Ireland Island (Papua New Guinea), Northern Australia.

Diagnosis and description. See Robillard et al. 2016.

Included species:

Macrobinthus jharnae (Bhowmik, 1981)

Macrobinthus kutini n. sp.

Macrobinthus newguineae (Bhowmik, 1981)

Macrobinthus songi Robillard \& Dong, 2016

Macrobinthus wilhelmsis Robillard \& Dong, 2016 


\section{Macrobinthus kutini n. sp.}

(Figs. 9B, 10G-I, 14-18)

http://lsid.speciesfile.org/urn:Isid:Orthoptera.speciesfile.org:TaxonName:500998

Type material. Male holotype: Australia, Queensland, Cooks Hut Camping Area, Portland Roads Rd Queensland, 11.v 2015, [D.] Yeates, [B.] Lessard, [K.] Meusemann \& [Y.N.] Su, molecular sample L121 (ANIC 14-005048). Female: Australia, Queensland, same information as HT, molecular sample L118 (ANIC 14 005048). Paratypes (1 $\delta^{\lambda}, 3$ ):

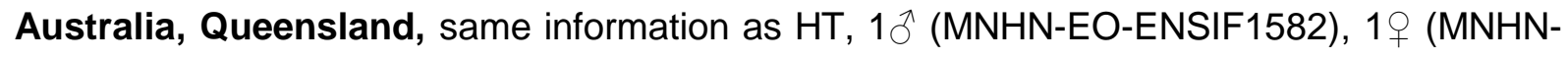
EO-ENSIF1495). Old Coen Track, Iron Range, Qld, 12²4'S 14315'E, 53 m, 13.v.2015, [D.] Yeates, [B.] Lessard, [K.] Meusemann \& [Y.N.] Su, 1q, molecular sample L124 (ANIC-14 005051). Gordon Creek, Iron Range, Qld, 1243'S 14318'E, 12.v.2015, 19, Zwick, Cocking, Edwards molecular sample L125 (ANIC 14-008493).

Type locality. Australia, Queensland, Kutini-Payamu (Iron Range) National Park, Cooks Hut Camping Area, Portland Roads Rd Queensland.

Distribution. Australia, Queensland.

Etymology. Species named after the type locality of Kutini-Payamu (Iron Range) National Park.

Diagnosis. Main characteristics as for the genus in terms of shape, coloration and FW venation. M. kutini is characterized by its large size, long FWs as in $M$. jharnae and male genitalia widened laterally, with paired globular pseudepiphallic lophi more developed than in M. jharnae.

Description. Size large. Coloration mostly dark brown and orange brown, contrasted (Fig. 14). Head rounded, eyes little protruding, occupying $38 \%$ of head width in dorsal view. Vertex with six wide longitudinal black bands on yellow background, sometimes almost fused together, the median ones punctuated (Fig. 15A); back of eyes with a yellow line. Fastigium orange brown, black apically; twice as wide as scape, slightly widened apically. Ocelli yellow. Scapes mottled with yellow and dark brown; antennae brown with yellow brown rings. Frons black, with a thin yellow median spot, face mostly dark brown with four yellow spots, mouthparts pale (Fig. 15B). Maxillary palpi brown with yellow rings. Pronotum: Dorsal disk dark brown to black, mottled with orange; lateral lobes homogeneously black. Brachypterous, FWs reaching one third of abdomen length in both sexes. FI-II orange brown with dark brown spots; TI-II dark brown with a narrow yellow ring; tarsomeres dark brown, yellow basally. Leg 
III orange brown basally, dark brown to black apically, including posterior parts of FIII, knee and TIII. Abdomen brown, variable. Cerci orange brown with dark brown rings.

Male: FWs narrow, dorsal and lateral fields gray brown, slightly translucent, with a small yellowish basal spot (not visible in fixed specimens); veins little contrasted (Fig. 16A). Vein $1 \mathrm{~A}$ not bisinuate, with a wide flat angle (ca. $120^{\circ}$ ). Harp longer than wide, its posterior corner slightly raised, with one bisinuate oblique vein, its inner sinuation angular, and one thin vein in anterior corner. CuA not curved inward, except for a slight sinuation near harp posterior angle. CuP absent. Mirror not differentiated from other cells of D alignment. Cell c1 widened posteriorly, with a faint transverse vein. Apical field almost as long as harp, including one cell alignment (E). Veins R, M and Sc orange, areas between them brown with yellow transverse veins. Lateral field with five or six $(n=2)$ strong parallel longitudinal veins ventral to Sc, with yellow transverse veins $(n=2)$.

Male genitalia (Fig. 17): Pseudepiphallus triangular, widened laterally, basal margin curved anteriorly; posterior apex with paired globular lophi, setose. Rami straight and short, slightly divergent. Pseudepiphallic parameres sclerotized, with two large posterior lobes oriented posteriorly, the dorsal the longest; and one basal lobe, membranous. Ectophallic apodemes divergent, long, their bases with expansions forming base of ventral ectophallic membranous lobes. Ectophallic arc complete, wide and straight. Ectophallic fold with lateral sclerites boneshaped, widened preapically; apex of ectophallic fold narrow and membranous. Endophallic sclerite comprising a short median expansion posteriorly and short lateral arms; sclerite very long anteriorly, exceeding anterior margin of pseudepiphallus. Endophallic apodeme comprising a narrow dorsal crest fused with narrow lateral lamellas.

Female. FWs almost as long as in male, generally slightly overlapping along half of their length, their apex rounded (Fig. 16B). FW cells black, not translucent, with strong dark brown to black longitudinal veins and weak yellow transverse ones; with 13-15 $(n=3)$ longitudinal veins, 7-8 on dorsal field, 6-7 on lateral field. Ovipositor slightly shorter than FIII, apex slightly rounded, not denticulate dorsally (Fig. 9B). Female copulatory papilla (Figs. 10G-I): rounded, convex ventrally; basal sclerite $\mathrm{C}$-shaped, with a triangular basal plate; apex rounded, slightly sclerotized and folded ventrally.

Juvenile: Unknown.

Measurements. See Table 3.

Habitat and life history traits. M. kutini was found active at night on the ground of forest tracks.

Calling song. Unknown. 


\section{Discussion}

In this study, we transferred the two existing species of Australian brachypterous Lebinthini to the tribe Eurepini (Lebinthus miripara and L. bifasciatus), based on reanalysis of the type material and their morphological features. These results suggest that the taxonomy and classification of the Eurepini should be revised using modern tools and standards for systematics.

We also described two new lineages of true Lebinthini from the north of Queensland (Fig. 18). One species, Macrobinthus kutini, belongs to the genus Macrobinthus recently described from New Guinea (Robillard et al. 2016). This finding is little surprising, since New Guinea and the north of Australia share a similar climate and are close together in terms of distance. It, however, represents the first exchange of species between the two territories documented amongst the brachypterous Lebinthini (the widely distributed species Cardiodactylus novaeguineae is widespread it the Western Pacific region, possibly because of its flight abilities and/or its coastal habitat; see Robillard \& Ichikawa 2009). The genus Macrobinthus is thus not endemic to New Guinea and surrounding islands, but also occurs in Australia. This likely corresponds to a recent colonization through the Torres Strait.

The second new lineage corresponds to the new genus Julverninthus. It represents original combinations of morphological characters, including puzzling similarities with the male genitalia of the genus Pixibinthus from New Caledonia. The current know distribution of Julverninthus is very limited and will need to be completed by further explorations of the Australian fauna to test whether is it restricted to a small area in Queensland or is wider. Such information will be necessary to discuss the origin of this lineage in Australia in respect to the other lineages of brachypterous Lebinthini present in New Guinea, New Caledonia and Vanuatu. Similarly, acoustic data will be needed to complement the knowledge on these new Australian taxa. Do they conform to the other Lebinthini in terms of system of communication, using high-frequency calls and female vibratory responses (after Hofstede et al. 2015), or do they correspond to a subsequent diversification of the tribe? Each new lineage of Lebinthini discovered during the last decade has indeed added new pieces to help understanding the diversity of eneopterine crickets and their communication systems.

\section{Acknowledgements}

We thank David Rentz for collecting and photographing specimens of Julverninthus; Susan Wright, Christine Lambkin and Geoff Thompson of the Queensland Museum for assistance and providing digital images, and Simon Poulain (CNRS) for taking pictures of the 
specimens. We thank Céline Bonillo (MNHN, Service de Systématique Moléculaire) (CNRS UMS2700), for the help using the extraction robot and for assistance with the DNA barcoding.

\section{References}

Anso, J., Barrabé, L., Desutter-Grandcolas, L., Jourdan, H., Grandcolas, P., Dong, J., Robillard, T. (2016) Old Lineage on an Old Island: Pixibinthus, a new cricket genus endemic to New Caledonia shed light on gryllid diversification in a hotspot of biodiversity. PLoS One, 11, e0150920.

Chopard, L. (1951) A revision of the Australian Grylloidea. Records of the South Australian Museum, 9, 397-533.

Chopard, L. (1968) In: Pars 12. Fam Gryllidae: Subfam. Mogoplistinae, Myrmecophilinae, Scleropterinae, Cachoplistinae, Pteroplistinae, Pentacentrinae, Phalangopsinae, Trigonidiinae, Eneopterinae. Fam. Oecanthidae, Gryllotalpidae. Dr. W. Junk N.V.'s Gravenhage, pp. 215-500.

Cigliano, M.M., H. Braun, D.C. Eades \& D. Otte. Orthoptera Species File. Version 5.0/5.0. [retrieved 30/09/2017]. <http://Orthoptera.SpeciesFile.org>.

Desutter, L. (1987) Structure et évolution du complexe phallique des Gryllidea (Orthoptera) et classification des genres néotropicaux de Grylloidea.1ère partie. Annales de la Société Entomologique de France (N.S.), 23, 213-239.

Desutter-Grandcolas, L. (2003) Phylogeny and the evolution of acoustic communication in extant Ensifera (Insecta, Orthoptera). Zoologica Scripta, 32, 525-561.

http://dx.doi.org/10.1046/j.1463-6409.2003.00142.xHall 1999

Nattier, R., Robillard, T., Desutter-Grandcolas, L., Couloux, A. \& Grandcolas, P. (2011) Older than New Caledonia emergence? A molecular phylogenetic study of the eneopterine crickets (Orthoptera: Grylloidea). Journal of Biogeography, 38, 2195-2209.

Nattier, R., Grandcolas, P., Elias, M., Desutter-Grandcolas, L., Jourdan, H., Couloux, A. \& Robillard, T. (2012) Secondary Sympatry Caused by Range Expansion Informs on the Dynamics of Microendemism in a Biodiversity Hotspot. PLoS One, 7, e48047.

Nguyen, L. T., Schmidt, H. A., Von Haeseler, A. \& Minh, B. Q. (2015) IQ-TREE: A Fast and Effective Stochastic Algorithm for Estimating Maximum-Likelihood Phylogenies. Molecular Biology and Evolution, 32, 268-274. 
Otte, D. \& Alexander, R. D. (1983) The Australian crickets. Monographs of the Academy of Natural Sciences of Philadelphia, 22, 1-477.

Robillard, T. (2006) Phylogenetic systematics of Pseudolebinthus, a new genus of Eneopterinae crickets (Orthoptera, Grylloidea, Eneopteridae) from south-east Africa. Systematic Entomology, 31, 671-683.

Robillard, T. (2011) Centuriarus n. gen., a new genus of Eneopterinae crickets from Papua (Insecta, Orthoptera, Grylloidea). Zoosystema, 33, 49-60.

Robillard, T., Dong, J., Legendre, F. \& Agauvoa, S. (2016) The brachypterous Lebinthini crickets from Papua New Guinea, with description of two new genera and four new species (Orthoptera: Gryllidae: Eneopterinae). In: T. Robillard, F. Legendre, C. Villemant \& M. Leponce (Eds), Insects of Mount Wilhelm, Papua New Guinea. Mémoires du Muséum national d'Histoire naturelle Paris, 109, pp. 149-202.

Robillard, T. \& Desutter-Grandcolas, L. (2004) Phylogeny and the modalities of acoustic diversification in extant Eneopterinae (Insecta, Orthoptera, Grylloidea, Eneopteridae). Cladistics, 20, 271-293.

Robillard, T. \& Desutter-Grandcolas, L. (2006) Phylogeny of the cricket subfamily Eneopterinae (Insecta, Orthoptera, Grylloidea, Eneopteridae) based on four molecular loci and morphology. Molecular Phylogenetics and Evolution, 40, 643-661.

Robillard, T. \& Ichikawa, A. (2009) Redescription of two Cardiodactylus species (Orthoptera, Grylloidea, Eneopterinae): the supposedly well-known C. novaeguineae (Haan, 1842), and the semi-forgotten C. guttulus (Matsumura, 1913) from Japan. Zoological Science, $26,878-891$.

Su, Y. N. (2016) A simple and quick method of displaying liquid-preserved morphological structures for microphotography. Zootaxa, 4208, 592-593.

ter Hofstede, H. M., Schöneich, S., Robillard, T. \& Hedwig, B. (2015) Evolution of a Communication System by Sensory Exploitation of Startle Behavior. Current Biology, $25,3245-3252$.

Vicente, N. M., Olivero, P., Lafond, A., Dong, J. \& Robillard, T. (2015) Gnominthus gen. nov., a new genus of crickets endemic to Papua New Guinea with novel acoustic and behavioral diversity (Insecta, Orthoptera, Gryllidae, Eneopterinae). Zoologischer Anzeiger - A Journal of Comparative Zoology, 258, 82-91.

Vicente, N., Kergoat, G. J., Dong, J., Yotoko, K., Legendre, F., Nattier, R., et al. (2017) In and out of the Neotropics: historical biogeography of Eneopterinae crickets. Journal of Biogeography, 44, 2199-2210. 


\section{Legends of figures and tables}

FIGURE 1. Salmanites miripara (Otte \& Alexander, 1983) n. comb.: male holotype in dorsal (A) and lateral (B) views; female paratype in dorsal (C) and lateral (D) views; head in dorsal $(E)$, facial $(F)$ and lateral $(F)$ views. Scale bar: $A-D, 5 \mathrm{~mm}$.

FIGURE 2. Salmanites miripara (Otte \& Alexander, 1983) n. comb.: male genitalia in dorsal $(A)$, ventral $(B)$, lateral $(C)$, dorso-lateral $(D)$ and ventro-lateral $(E)$ views. Scale bar: $0.5 \mathrm{~mm}$.

FIGURE 3. Eurepa bifasciata (Chopard, 1951) n. comb.: female allotype in dorsal (A) and lateral (B) views; male in dorsal (C) and lateral (D) views; base of abdomen of female paratype (E); dorsal view of female FWs (non type) (F); face (G); male FW in dorsal view (holotype) (H). Scale bars: A-D, G, H, $5 \mathrm{~mm}$; E-F, $1 \mathrm{~mm}$. Photos A, B, E (C) Queensland Museum, Geoff Thompson.

FIGURE 4. Eurepa bifasciata (Chopard, 1951) n. comb.: male genitalia in dorsal (A), ventral (B), lateral (C), dorso-lateral (D) and ventro-lateral (E) views. Scale bar: $0.5 \mathrm{~mm}$.

FIGURE 5. Julverninthus rentzi n. sp. (A-D): male in dorsal (A) and lateral (B) views; female in dorsal (C) and lateral (D) views. Julverninthus minoris n. sp. (E-H): male in dorsal (E) and lateral $(F)$ views; female in dorsal $(G)$ and lateral $(H)$ views. Scale bar: $1 \mathrm{~cm}$.

FIGURE 6. Julverninthus rentzi n. sp. (A-C), Julverninthus minoris n. sp. (D-F): head in dorsal $(A, D)$, facial $(B, E)$ and lateral $(C, F)$ views, respectively. Scale bar: $1 \mathrm{~mm}$.

FIGURE 7. Julverninthus rentzi n. sp. (A-B): male forewing venation in dorsal view (A); female venation in dorsal view (B). Julverninthus minoris $\mathrm{n}$. $\mathrm{sp}$. (C): male forewing venation in dorsal view. Scale bar: $1 \mathrm{~mm}$.

FIGURE 8. Julverninthus rentzi n. sp.: male genitalia in dorsal (A), ventral (B) and lateral (C) views, with detail of posterior part in ventral view (D). Legends, see matetials and methods section. Scale bars: $1 \mathrm{~mm}$.

FIGURE 9. Julverninthus rentzi n. sp. (A), Macrobinthus kutini n. sp. (B): apex of ovipositor. Scale bar: $1 \mathrm{~mm}$. 
FIGURE 10. Julverninthus rentzi n. sp. (A-C), Julverninthus minoris n. sp. (D-F), Macrobinthus kutini n. sp. (G-I): female copulatory papilla in ventral $(A, D, G)$, dorsal (B, E, $\mathrm{H})$ and lateral $(\mathrm{C}, \mathrm{F}, \mathrm{I})$ views. Scale bar: $0.5 \mathrm{~mm}$.

FIGURE 11. Julverninthus rentzi n. sp.: male holotype in natural habitat (Photo (c) David Rentz).

FIGURE 12. Julverninthus rentzi n. sp.: couple mating on vegetation (A); juvenile on leaf (B) in natural habitat (Photos @ D David Rentz).

FIGURE 13. Julverninthus minoris n. sp.: male genitalia in dorsal (A), ventral (B) and lateral (C) views. Scale bar: $1 \mathrm{~mm}$.

FIGURE 14. Macrobinthus kutini n. sp.: male in dorsal (A) and lateral (B) views; female in dorsal (C) and lateral (D) views. Scale bar: $1 \mathrm{~cm}$.

FIGURE 15. Macrobinthus kutini n. sp.: head in dorsal (A), facial (B) and lateral (C) views. Scale bar: $1 \mathrm{~mm}$.

FIGURE 16. Macrobinthus kutini n. sp.: male forewing venation in dorsal view (A); female forewing venation in dorsal view (B). Scale bar: $1 \mathrm{~mm}$.

FIGURE 17. Macrobinthus kutini n. sp.: male genitalia in dorsal (A), ventral (B) and lateral (C) views, with detail of posterior part in ventral view (D). Scale bars: $1 \mathrm{~mm}$.

FIGURE 18. Distribution map of the species mentioned in the study. Map modified after snapshots from www.maphill.com. 
Table 1. Measurements of Julverninthus rentzi n. sp.

\begin{tabular}{|c|c|c|c|c|c|c|c|c|c|c|c|c|c|}
\hline & \multirow{2}{*}{ PronL } & \multirow{2}{*}{ PronW } & \multirow{2}{*}{ FWL } & \multirow{2}{*}{ FWW } & \multirow{2}{*}{ FIIIL } & \multirow{2}{*}{ FIIIW } & \multirow{2}{*}{ TIIIL } & \multicolumn{4}{|c|}{ TIIIS } & \multirow{2}{*}{ Tallls } & \multirow{2}{*}{$\mathrm{OL}$} \\
\hline & & & & & & & & las & $\mathrm{Ibs}$ & Oas & Obs & & \\
\hline Male holotype & 3.8 & 5.1 & 4.1 & 2.9 & 15.8 & 4.9 & 13.7 & 9 & 6 & 12 & 9 & 3 & - \\
\hline (Male mean) & (3.9) & (5) & $(4.6)$ & (3) & (15.2) & $(4.7)$ & (12.8) & (8) & (7) & (13) & (9) & (3) & - \\
\hline Female allotype & 4.1 & 5.5 & 1.6 & - & 16.6 & 5.5 & 14.7 & 6 & 8 & 11 & 9 & 3 & 14.2 \\
\hline
\end{tabular}

Table 2. Measurements of Julverninthus minorisi n. sp.

\begin{tabular}{|c|c|c|c|c|c|c|c|c|c|c|c|c|c|}
\hline & PronL & PronW & FWL & FWW & FIIIL & FIIIW & TIIIL & \multicolumn{4}{|c|}{ TIlls } & Tallls & $\mathrm{OL}$ \\
\hline Male holotype & 3.2 & 4.2 & 3.6 & 2.3 & 11.7 & 3.7 & 9.7 & 6 & 5 & 11 & 8 & $5(+1)$ & - \\
\hline Females $(n=2)$ & $3.2-3.7$ & $4.5-5$ & $0.9-1.2$ & - & $11.9-13.9$ & $4.1-4.2$ & $9.7-12$ & $6-7$ & 6 & $11-12$ & $5-9$ & $3-4(+1)$ & $10.9-11.2$ \\
\hline (Female mean) & (3.5) & $(4.8)$ & $(1.1)$ & - & (12.9) & $(4.2)$ & (10.9) & (7) & (6) & (12) & (7) & $(4+1)$ & (11.1) \\
\hline
\end{tabular}

Table 3. Measurements of Macrobinthus kutini n. sp.

\begin{tabular}{|c|c|c|c|c|c|c|c|c|c|c|c|c|c|}
\hline & \multirow{2}{*}{ PronL } & \multirow{2}{*}{ PronW } & \multirow{2}{*}{ FWL } & \multirow{2}{*}{ FWW } & \multirow{2}{*}{ FIIIL } & \multirow{2}{*}{ FIIIW } & \multirow{2}{*}{ TIIIL } & \multicolumn{4}{|c|}{ TIlls } & \multirow{2}{*}{ Tallss } & \multirow{2}{*}{ OL } \\
\hline & & & & & & & & Ias & Ibs & Oas & Obs & & \\
\hline Male holotype & 4 & 5.2 & 5.9 & 3.6 & 17.1 & 5.7 & 14.1 & 8 & 6 & 11 & 6 & 4 & - \\
\hline (Male mean) & (4.1) & (5.4) & (6.0) & (3.6) & (17.7) & (5.8) & $(14.7)$ & (7) & (6) & (11) & (6) & (4) & - \\
\hline Female allotype & 4.1 & 5.8 & 4.9 & 2.8 & 18.5 & 5.7 & 16 & 7 & 6 & 13 & 6 & 4 & 15.5 \\
\hline Females $(n=5)$ & 4.1-4.5 & $5.8-6.5$ & $4.5-5$ & $2.8-3.3$ & $18.5-18.9$ & $5.7-6.3$ & $15.8-16.6$ & 7-9 & $5-6$ & $10-13$ & $6-7$ & $3-4$ & $15.5-18.1$ \\
\hline
\end{tabular}




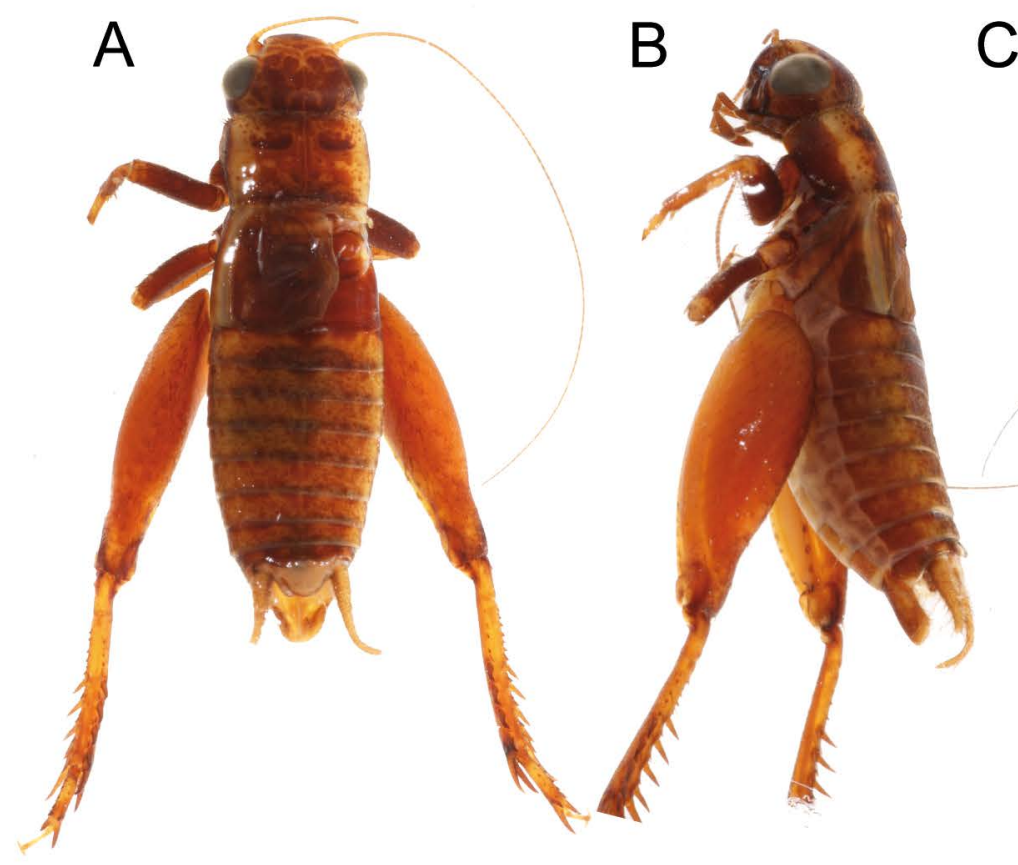

C

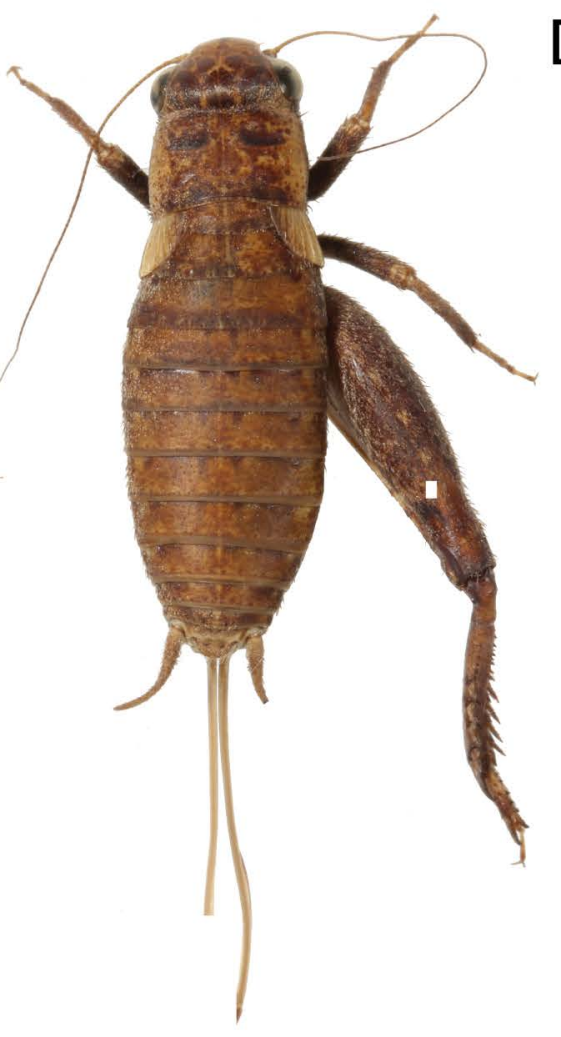

D

E
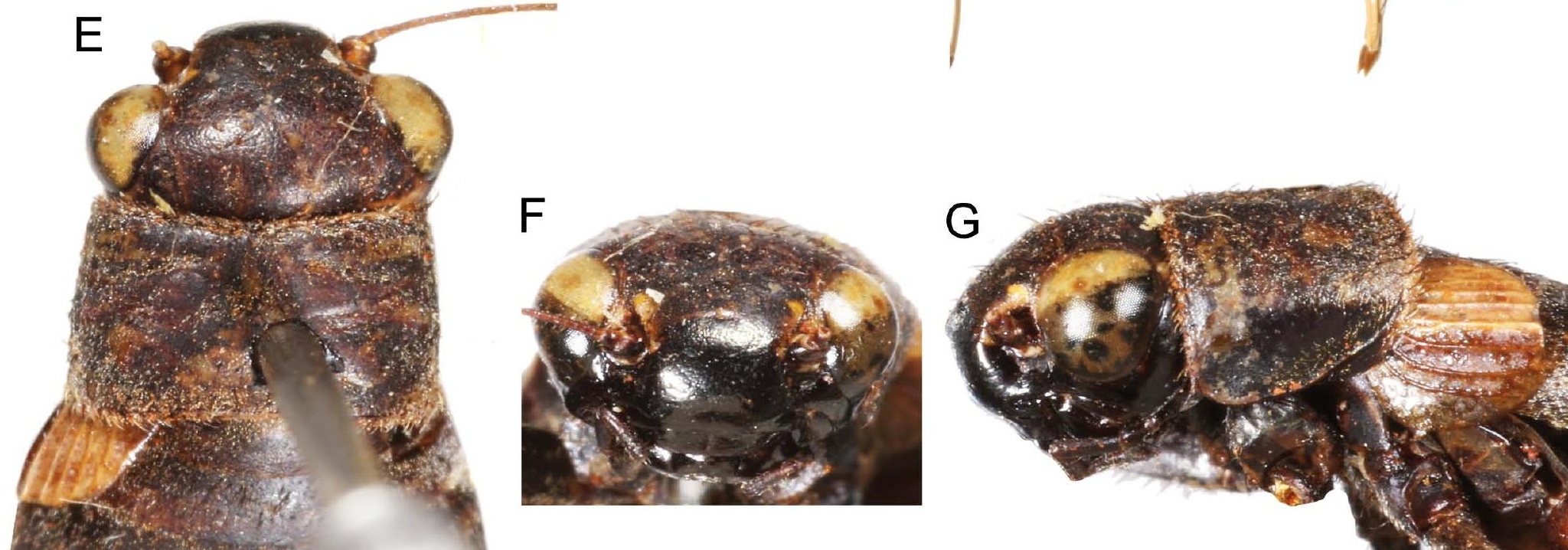
A

D

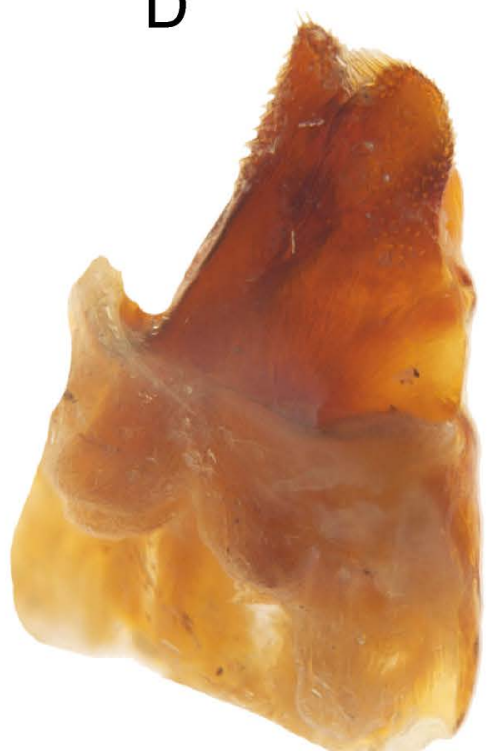

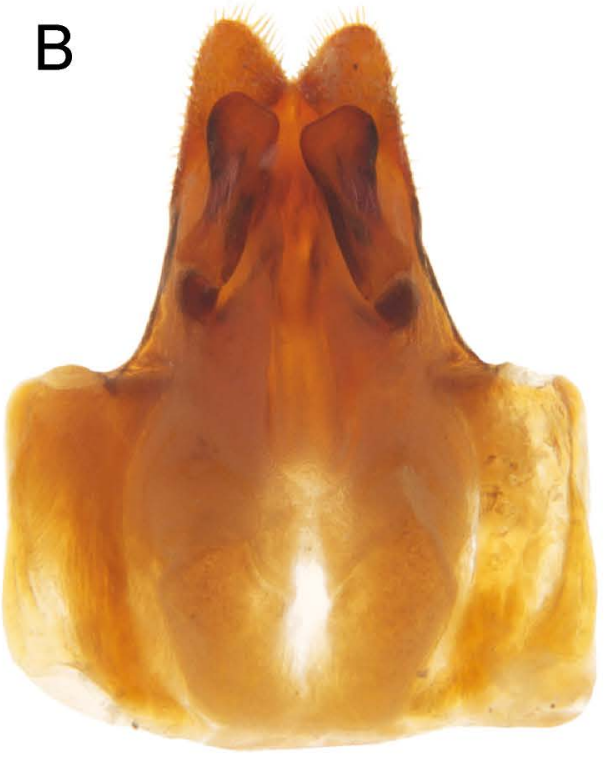

C

E

E

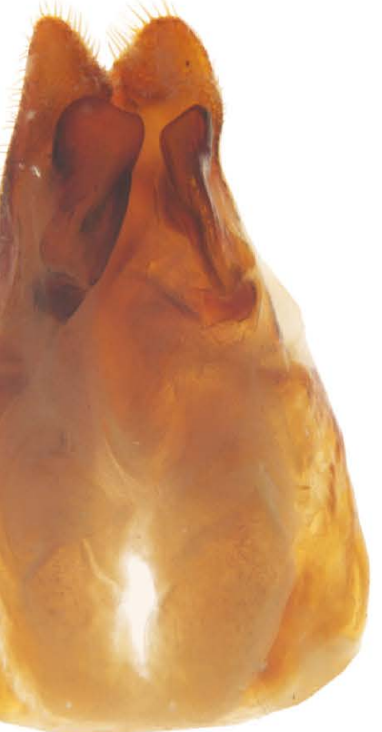




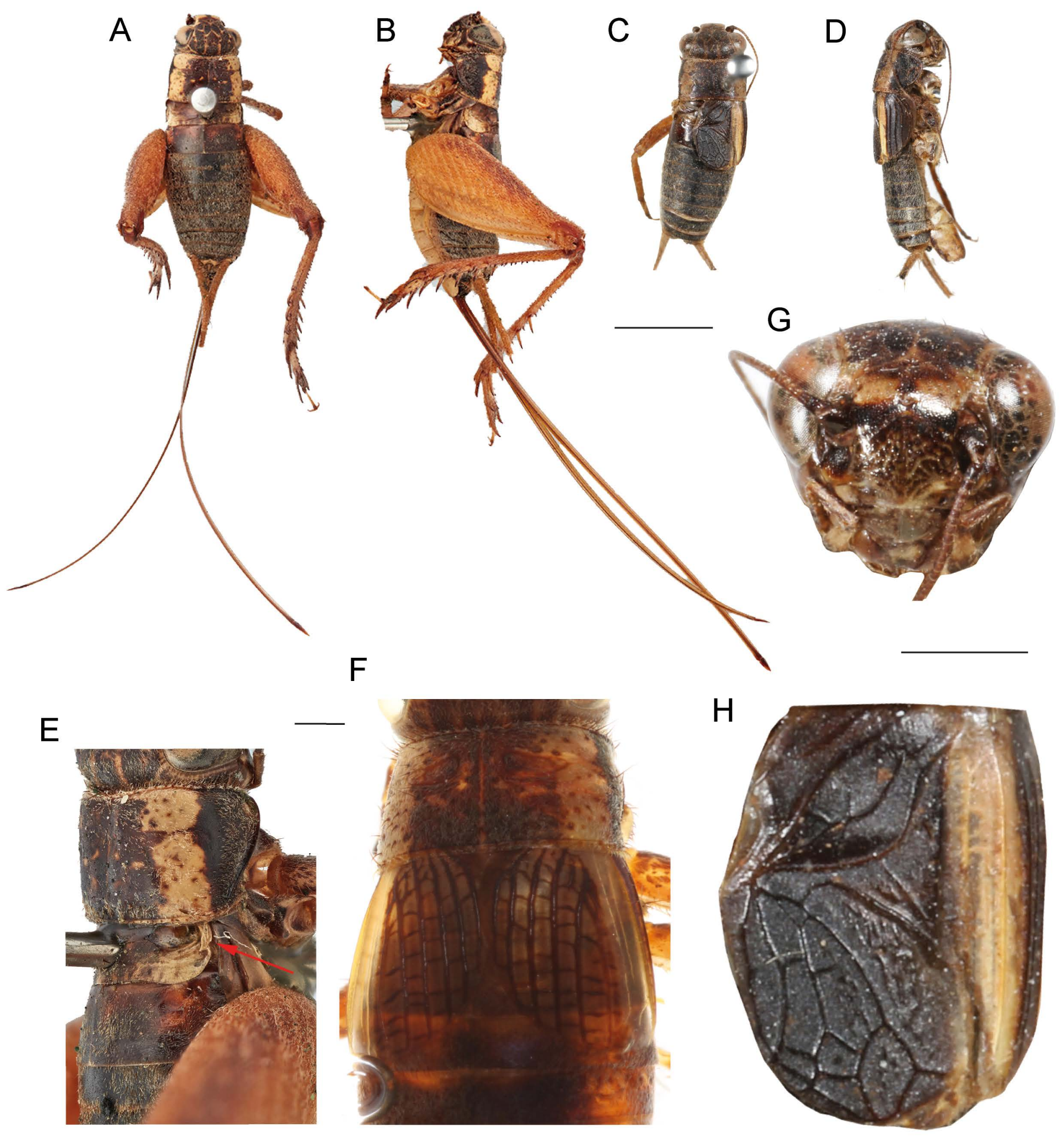




\section{A}
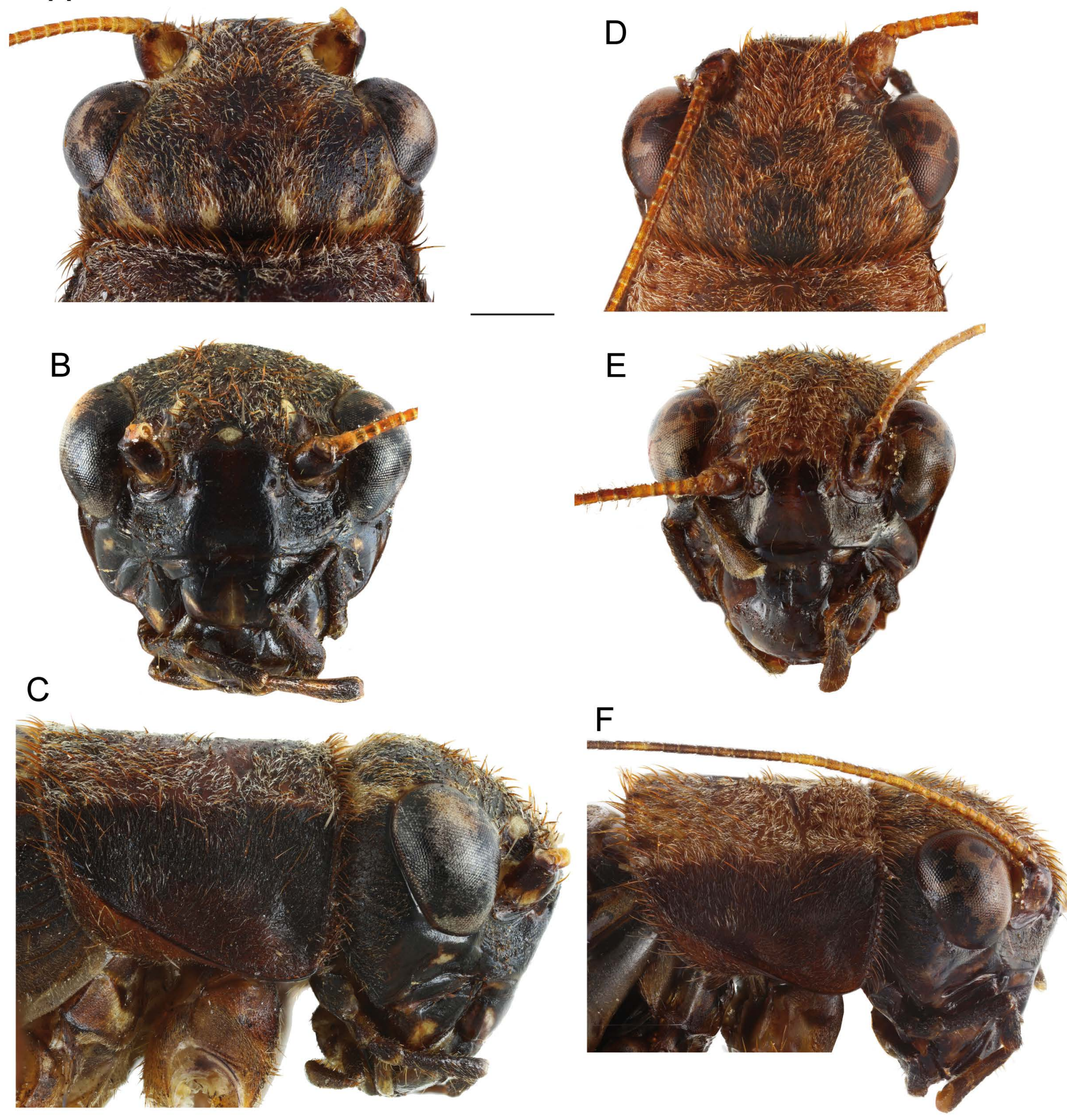


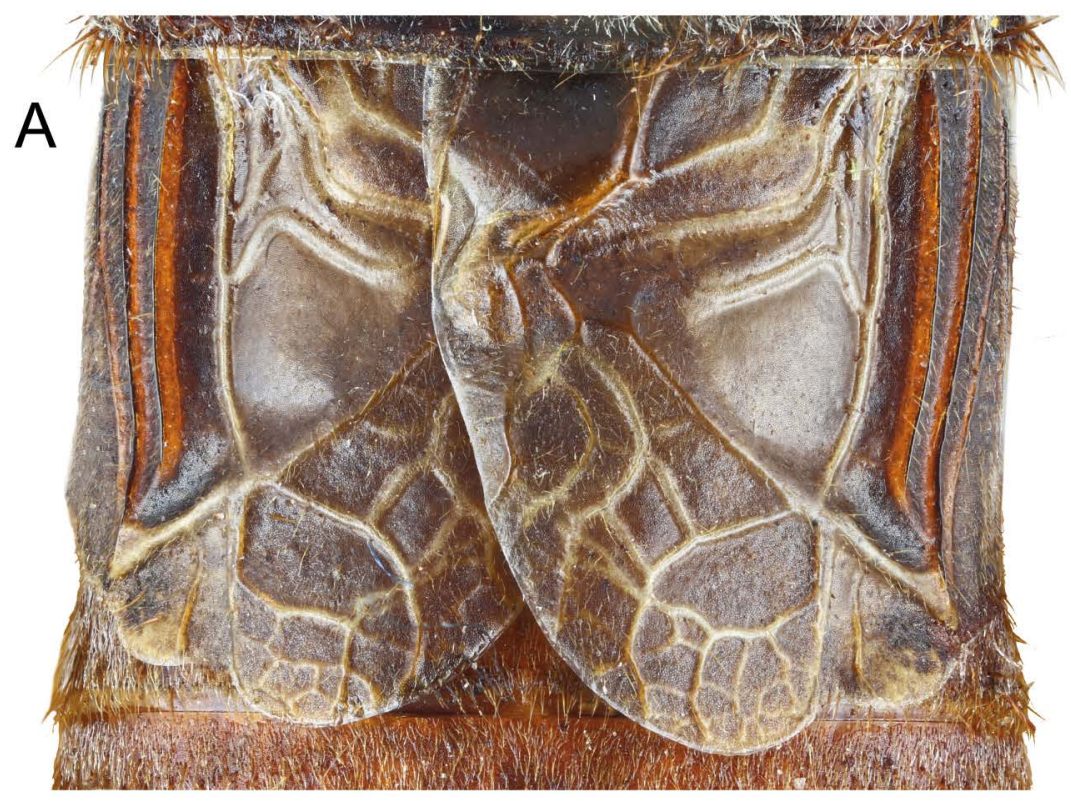

B

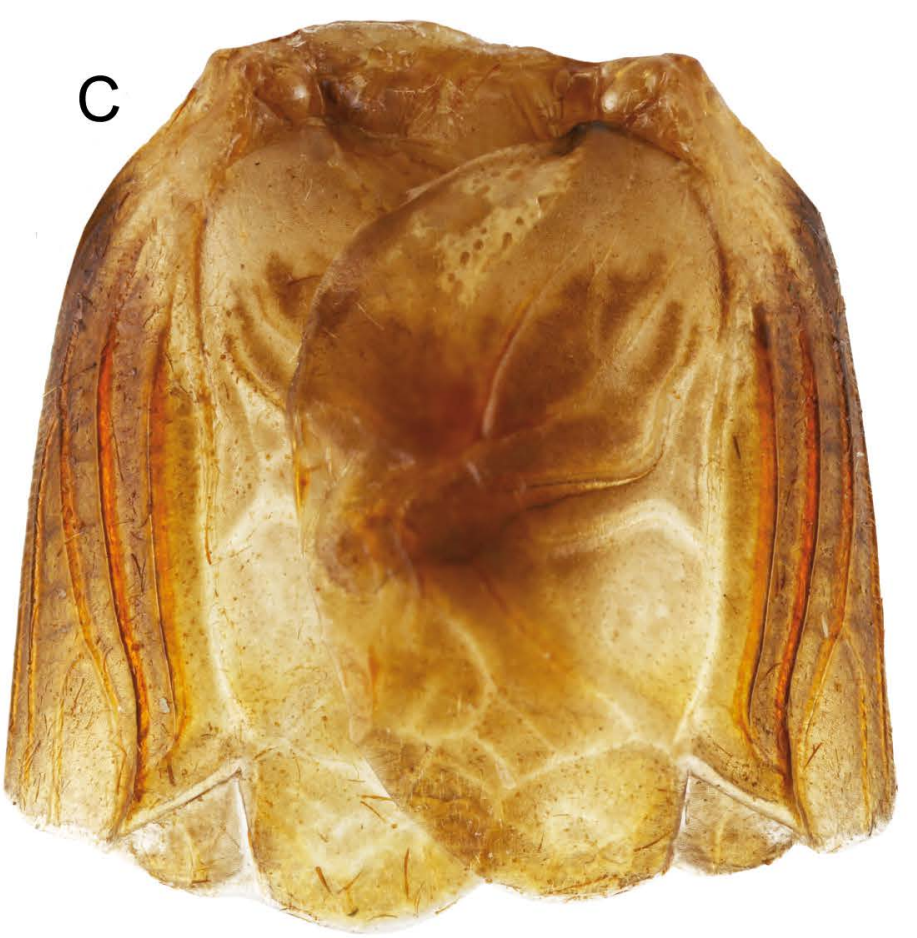

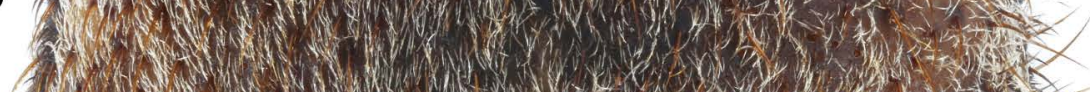

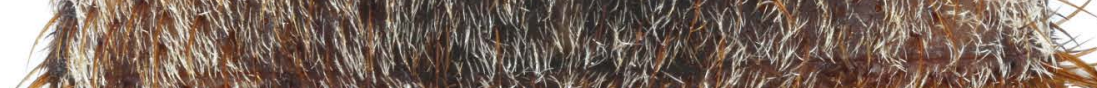

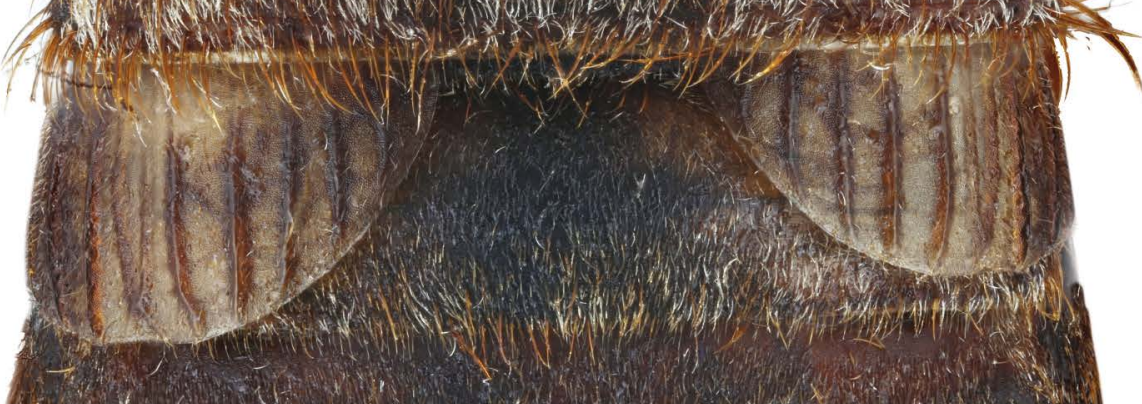



A

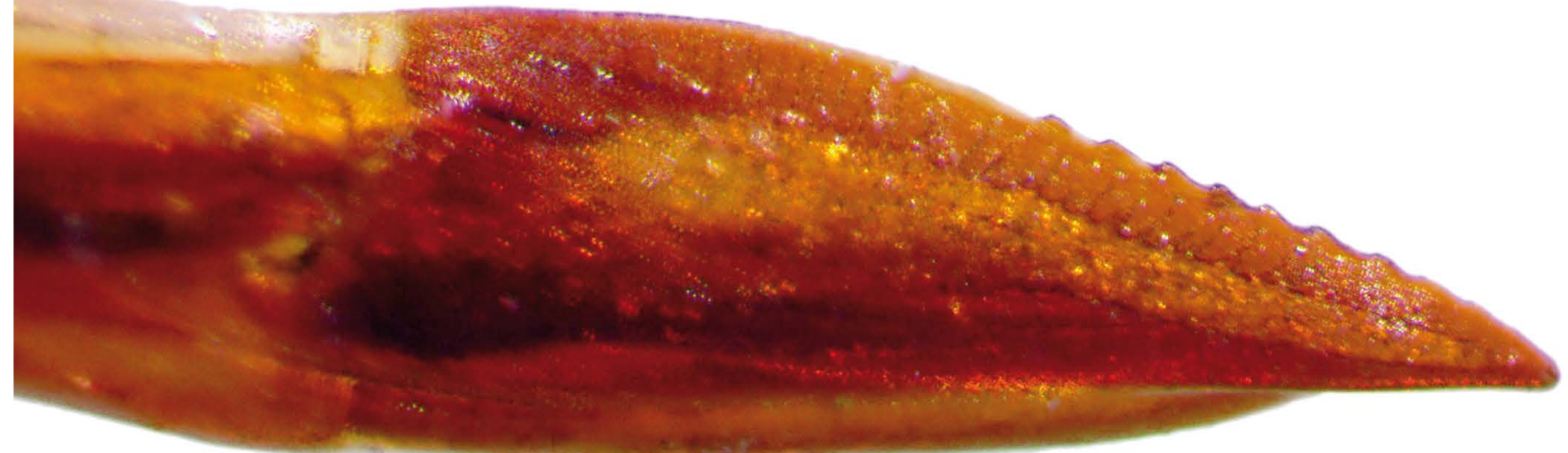

B

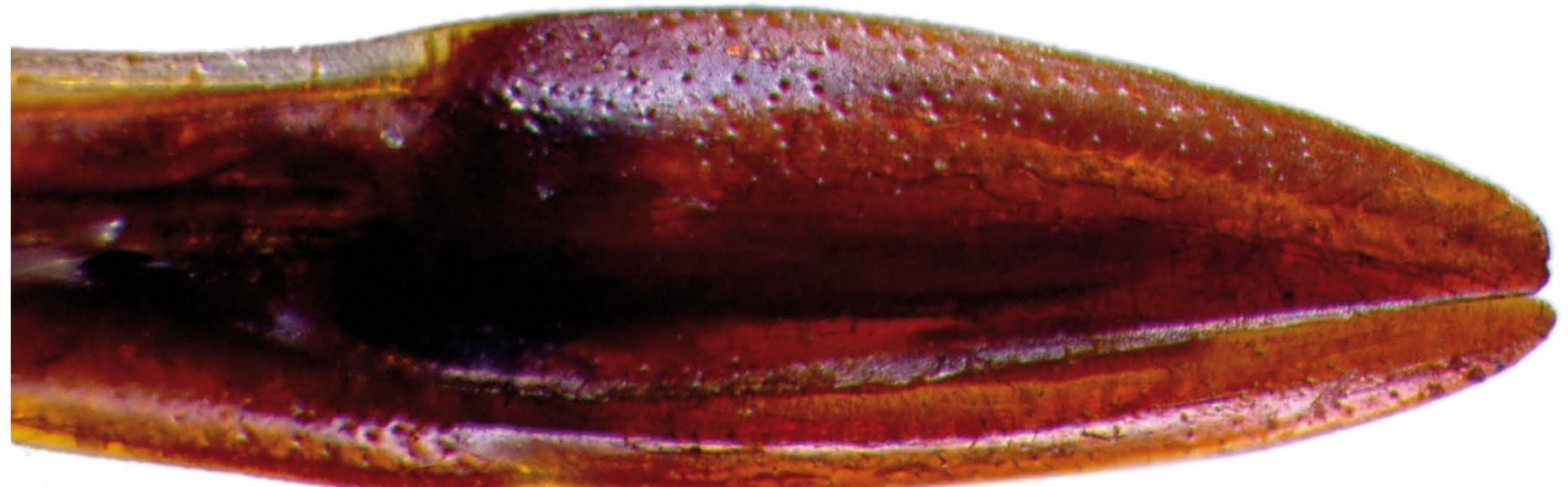


A

B

D

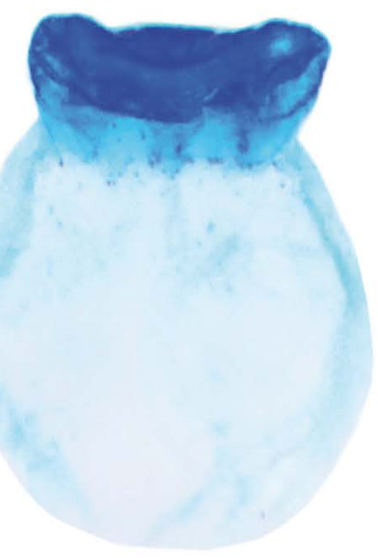

G

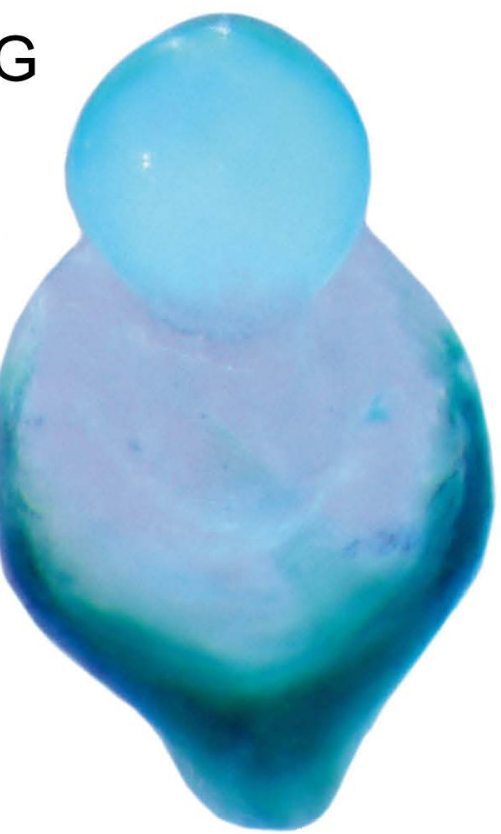

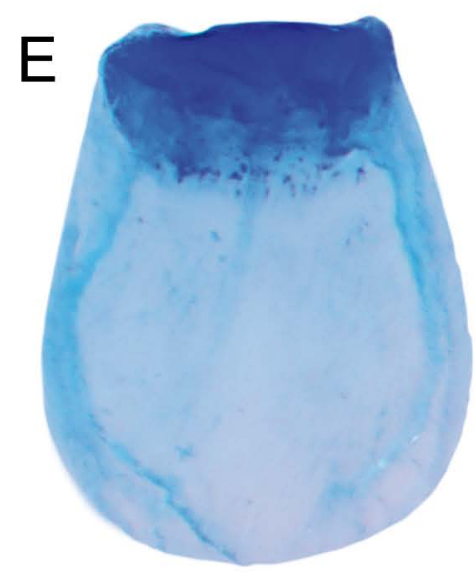

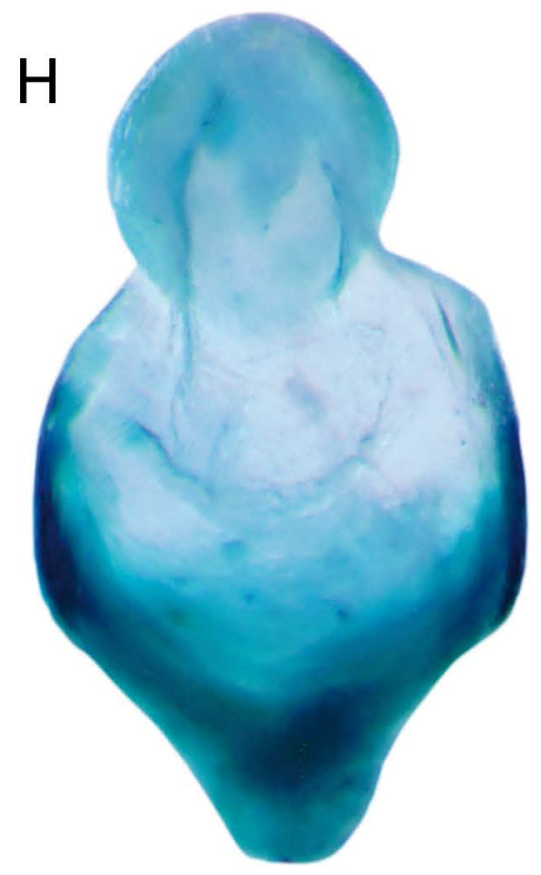

C

F
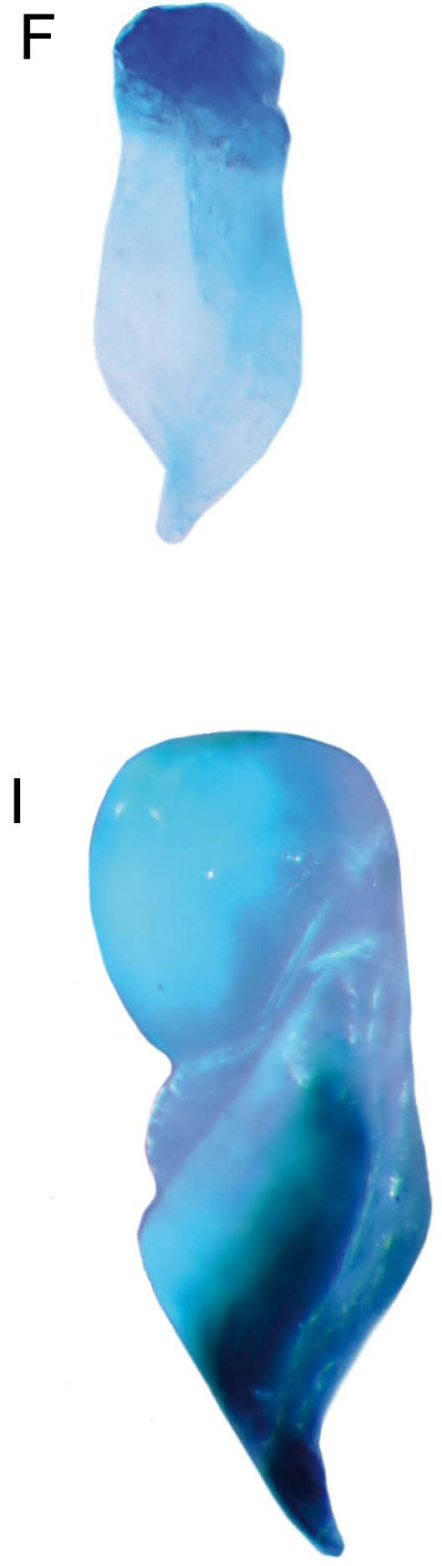


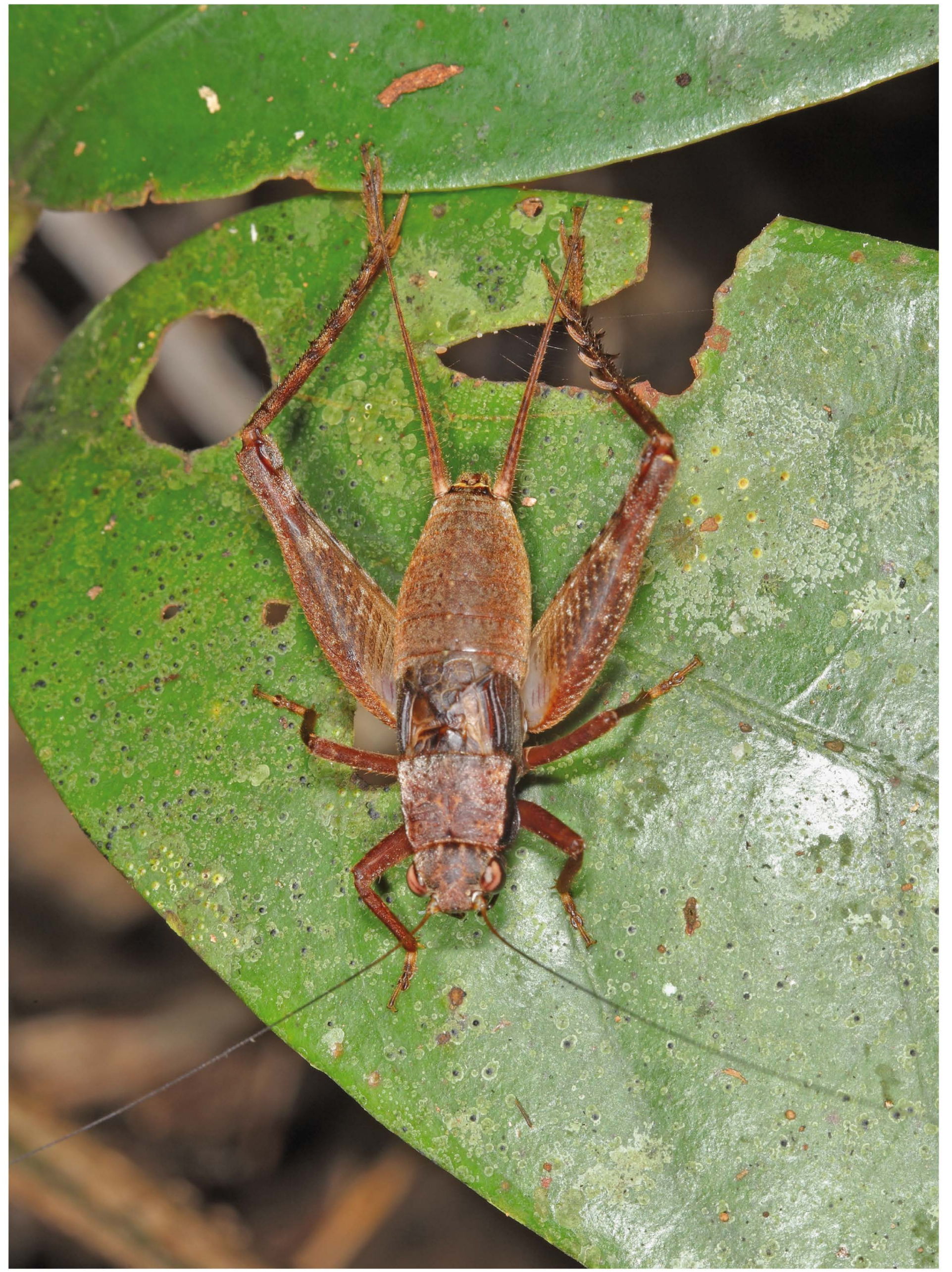


$A$

B
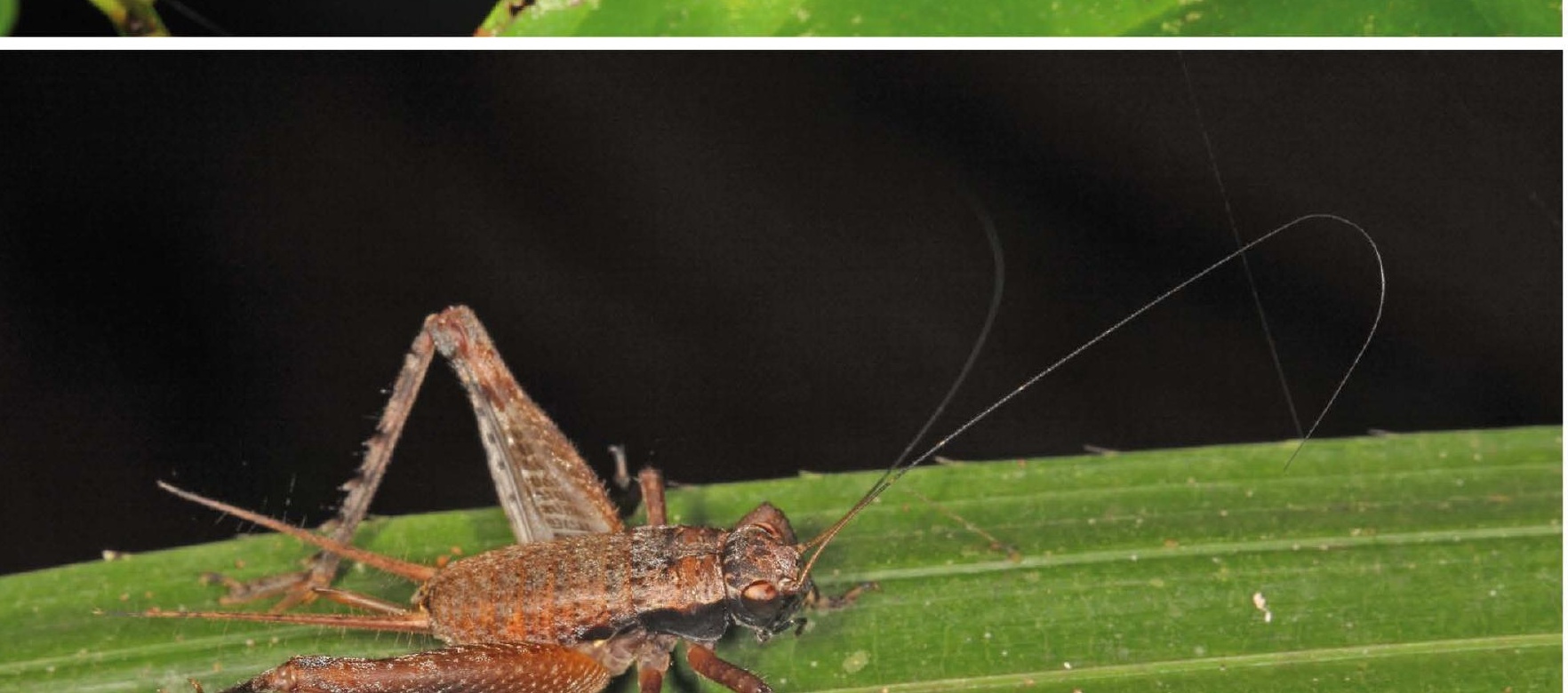

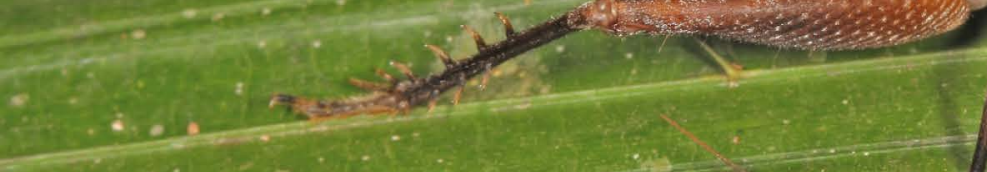
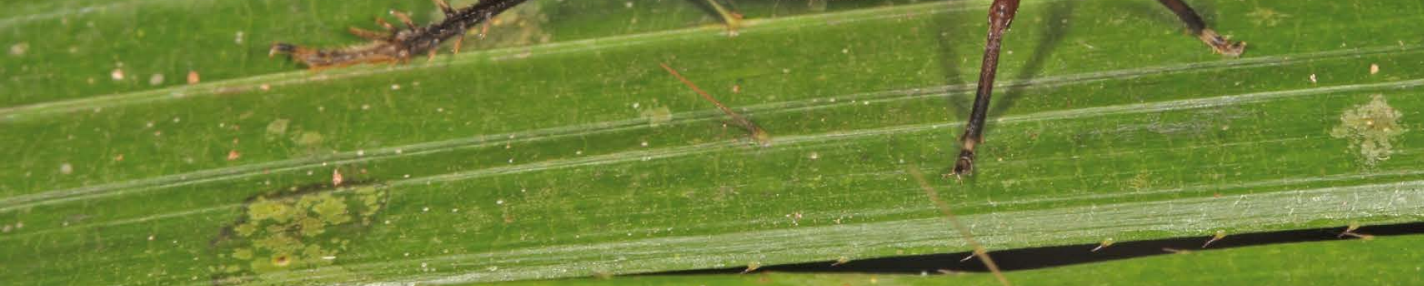

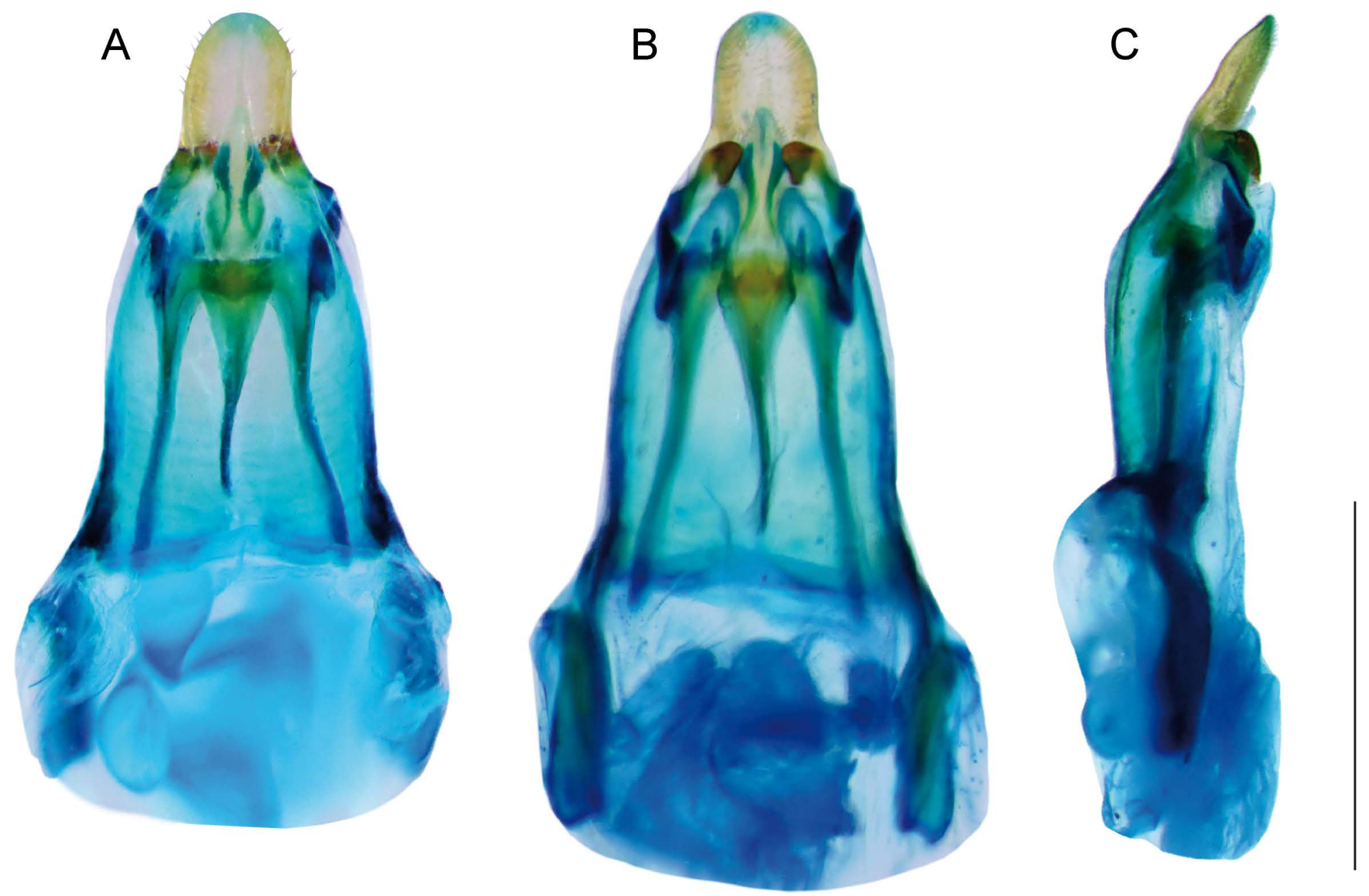

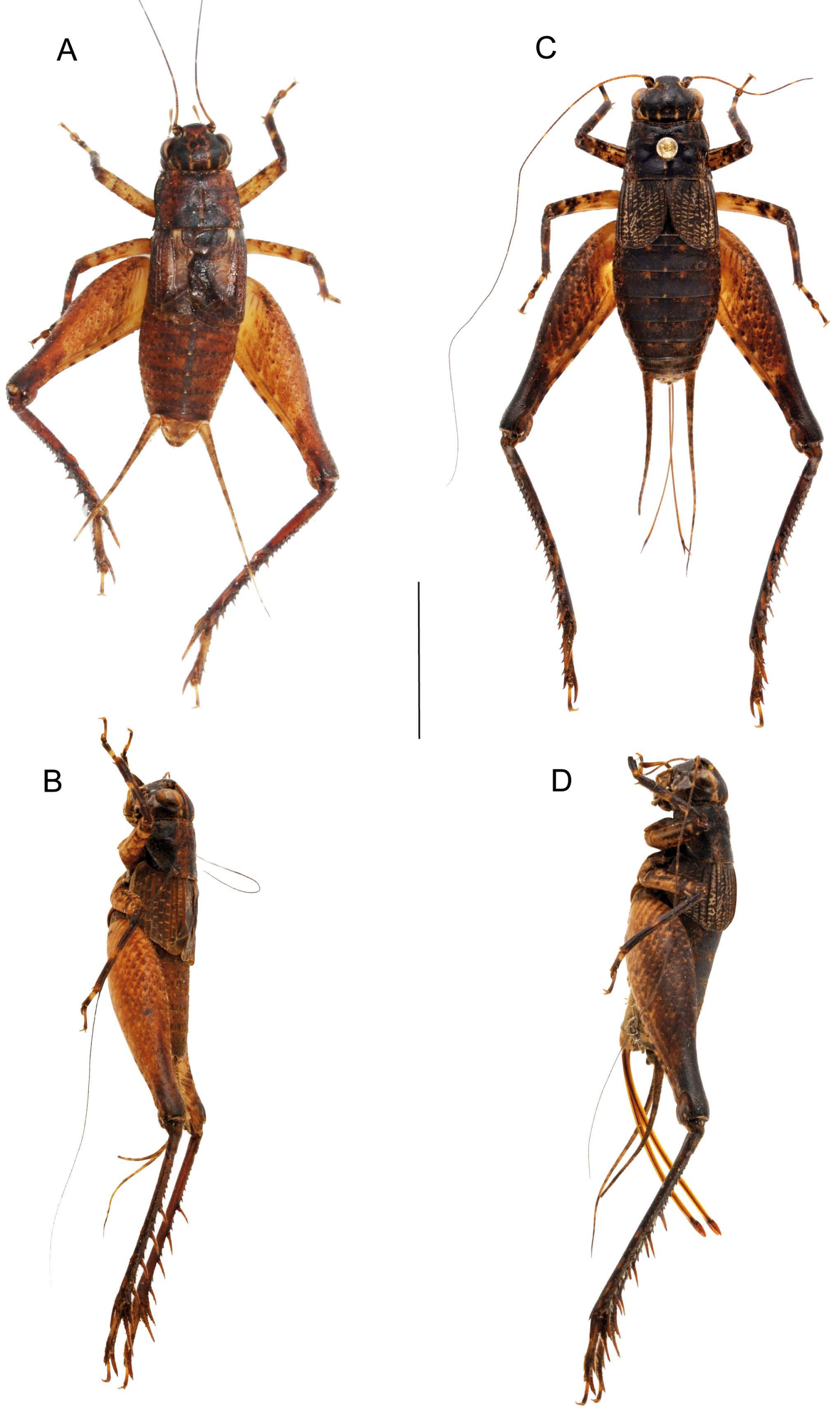

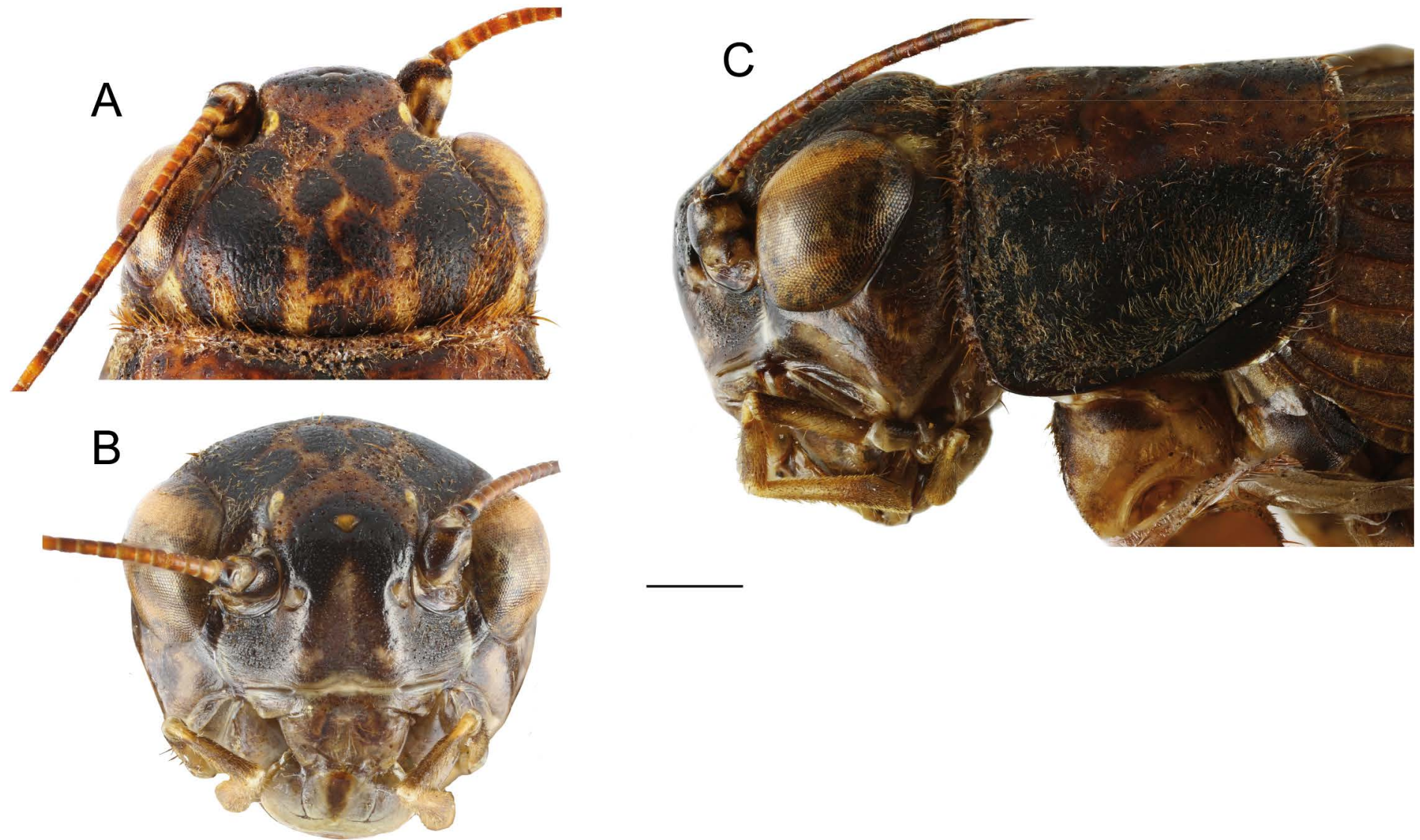


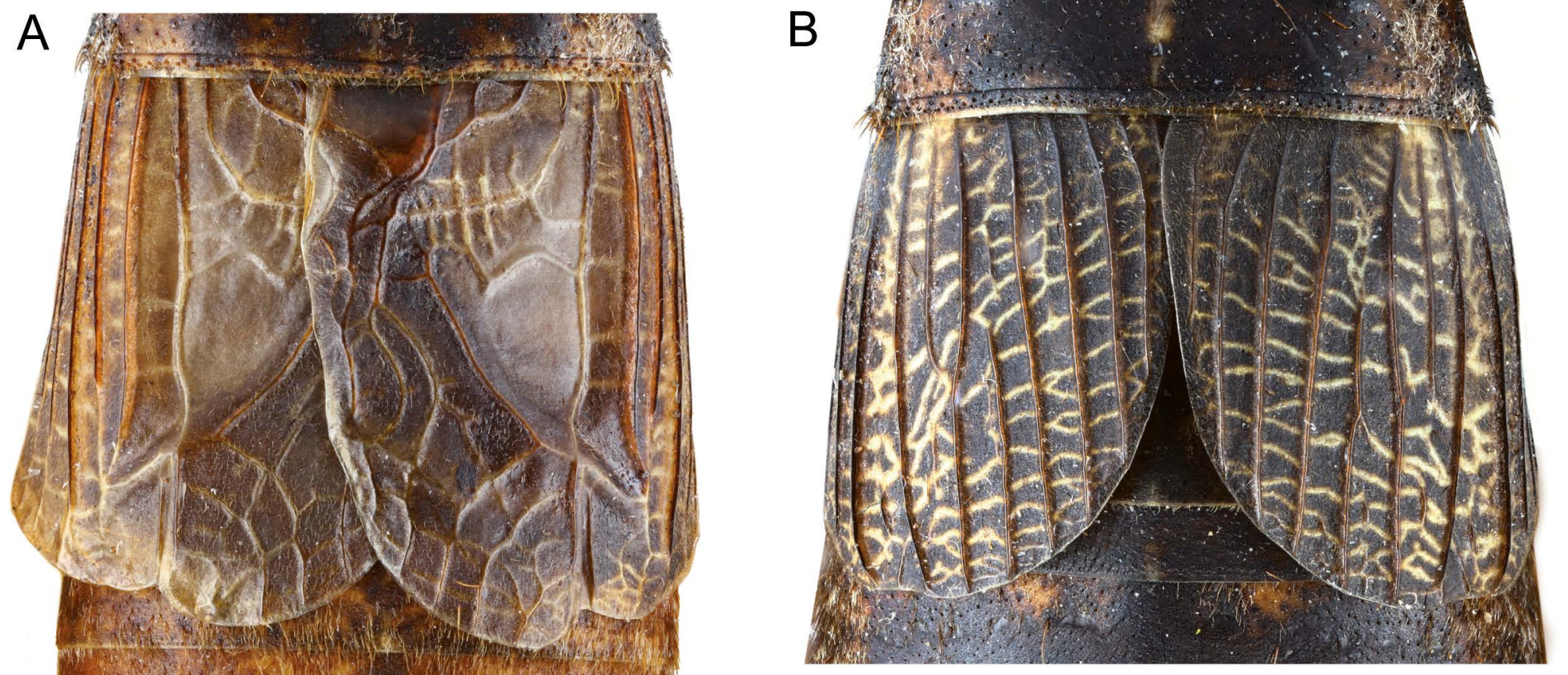



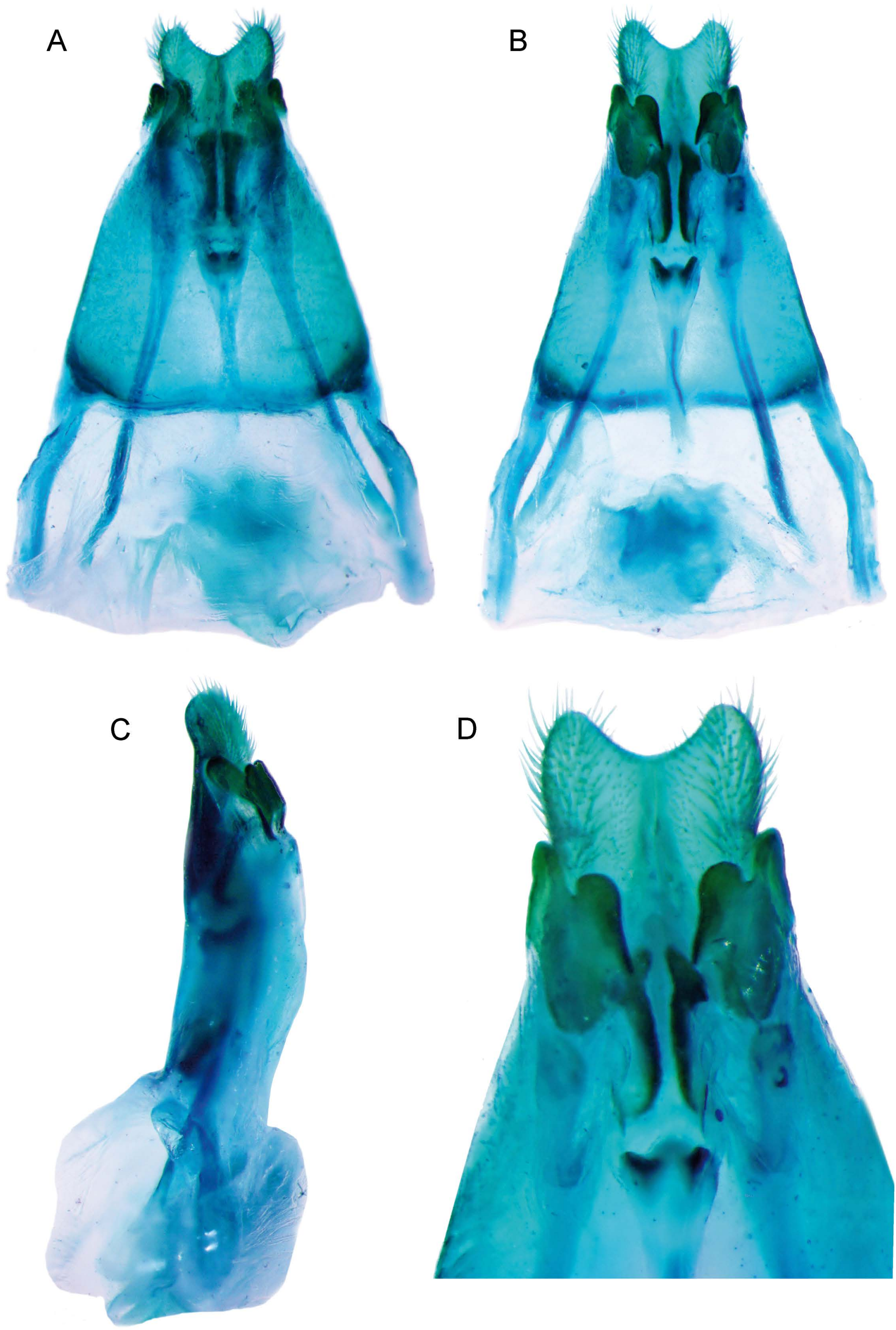


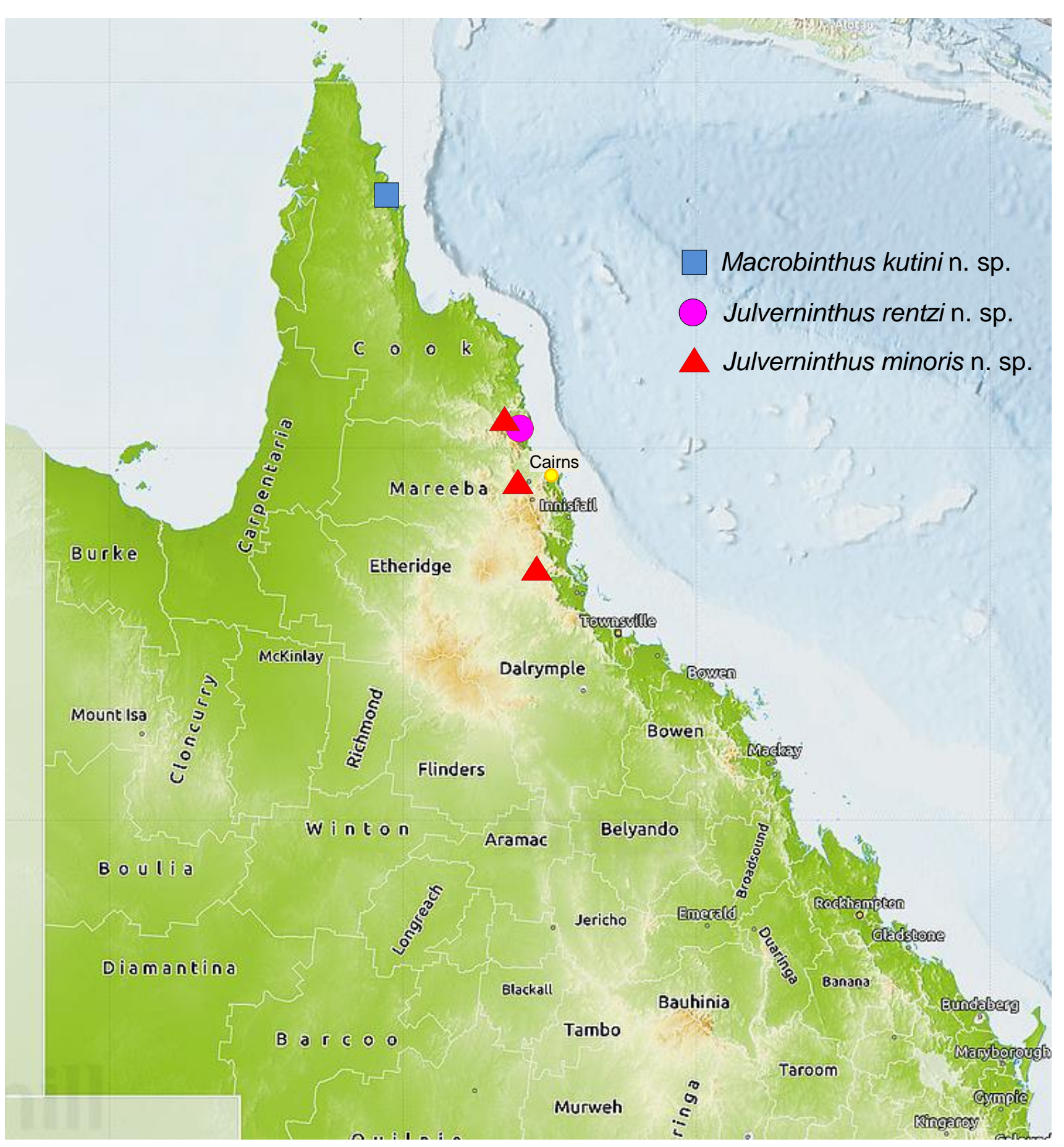

